Article

\title{
Design and Application of Magnetic Photocatalysts for Water Treatment. The Effect of Particle Charge on Surface Functionality
}

\author{
Anna Zielińska-Jurek ${ }^{1, *}$, Zuzanna Bielan ${ }^{1}$, Szymon Dudziak ${ }^{1}{ }^{(D)}$, Izabela Wolak ${ }^{1}$, \\ Zuzanna Sobczak $^{2}$, Tomasz Klimczuk ${ }^{2}$, Grzegorz Nowaczyk ${ }^{3}$ and Jan Hupka ${ }^{1}$ \\ 1 Department of Chemical Technology, Faculty of Chemistry, Gdansk University of Technology (GUT), \\ G. Narutowicza 11/12, 80-233 Gdansk, Poland; bielan_chan@onet.eu (Z.B.); dudziakszy@gmail.com (S.D.); \\ izawolak@wp.pl (I.W.); jhupka@pg.gda.pl (J.H.) \\ 2 Department of Solid State Physics, Faculty of Applied Physics and Mathematics, Gdansk University of \\ Technology (GUT), 80-233 Gdansk, Poland; zuzsobcz@gmail.com (Z.S.); tomklimc@pg.edu.pl (T.K.) \\ 3 NanoBioMedical Center, Adam Mickiewicz University, Umultowska 85, 61-614 Poznan, Poland; \\ grzegorznowaczyk76@gmail.com \\ * Correspondence: annjurek@pg.gda.pl
}

Received: 6 October 2017; Accepted: 21 November 2017; Published: 27 November 2017

\begin{abstract}
Core-interlayer-shell $\mathrm{Fe}_{3} \mathrm{O}_{4} / \mathrm{SiO}_{2} / \mathrm{TiO}_{2}, \mathrm{CoFe}_{2} \mathrm{O}_{4} / \mathrm{SiO}_{2} / \mathrm{TiO}_{2}$ and $\mathrm{BaFe}_{12} \mathrm{O}_{19} / \mathrm{SiO}_{2} / \mathrm{TiO}_{2}$ magnetic photocatalysts were obtained. A water-in-oil microemulsion system with suitable surfactants was used for functionalization of the magnetic core with silica interlayer and $\mathrm{TiO}_{2}$-based photocatalyst. Uncoated and coated particles were characterized by electrophoretic measurements, $\mathrm{X}$-ray diffractometry (XRD), scanning electron microscopy (SEM), transmission electron microscopy (TEM), specific surface area (BET) measurements, diffuse reflectance spectroscopy (DRS) and vibrating sample magnetometer (VSM) analysis. The $\mathrm{pH}$ of the solution and corresponding zeta potential was found to be essential for appropriate formation of ferrite core/silica interlayer $/ \mathrm{TiO}_{2}$ shell nanocomposite, since the electrical charge controls interactions during functionalization of the magnetic core particles. Thus, the development of multilayer structure in the isoelectric point (IEP) region enhanced adhesion of ferrite, silica and titania particles. The obtained $\mathrm{Fe}_{3} \mathrm{O}_{4} / \mathrm{SiO}_{2} / \mathrm{TiO}_{2}, \mathrm{CoFe}_{2} \mathrm{O}_{4} / \mathrm{SiO}_{2} / \mathrm{TiO}_{2}$ and $\mathrm{BaFe}_{12} \mathrm{O}_{19} / \mathrm{SiO}_{2} / \mathrm{TiO}_{2}$ nanocomposites revealed superparamagnetic behavior. The decomposition rate of phenol and carbamazepine allowed to estimate their photocatalytic activity. Progress of photocatalytic mineralization of organic compounds was evaluated by total organic carbon (TOC) measurements. Photocatalytic activity measured in four subsequent cycles showed good reusability as no loss of efficiency of phenol degradation was observed.
\end{abstract}

Keywords: heterogeneous photocatalysis; magnetic photocatalysts; $\mathrm{Fe}_{3} \mathrm{O}_{4} / \mathrm{SiO}_{2} / \mathrm{TiO}_{2} ; \mathrm{CoFe}_{2} \mathrm{O}_{4} / \mathrm{SiO}_{2} / \mathrm{TiO}_{2}$; $\mathrm{BaFe}_{12} \mathrm{O}_{19} / \mathrm{SiO}_{2} / \mathrm{TiO}_{2}$; core-shell structure; reusability; zeta potential

\section{Introduction}

UV-vis light driven photooxidation of persistant organic pollutants [1-3], removal of odors from enclosed space [4], destruction of bacteria with low intensity radiation [5] and self-cleaning surfaces [6] are examples of the potential of nanostructure-based photocatalysts. One of major challenges in photocatalysis application is separation and recovery of nanosized $\mathrm{TiO}_{2}$ particles from the treated water, since sedimentation is usually insufficient, while filtration is costly [7]. Even if coagulation, flocculation or centrifugation is used, the supernatant may not be clear. In the past decade, much effort was devoted to photocatalyst immobilization on Raschig rings, glass tubes, glass beads, glass fiber, zeolites and activated carbon [8-10]. However, immobilized $\mathrm{TiO}_{2}$ was less active due to lower specific surface area in such systems. 
In this regard, preparation of well performing and readily separable photocatalysts is a priority in heterogeneous photocatalysis. Mesoporous titania micro- and sub-micro spheres, hierarchical $\mathrm{TiO}_{2}$ micro-sized particles were proposed for photodegradation of organic contaminants facilitating its reuse [11-13]. Furthermore, to ease separation, composites consisting of a magnetic core and photoactive shell have been also developed. Already in 1994 Hiroshi and coworkers patented a preparation of $\mathrm{Fe}_{3} \mathrm{O}_{4} / \mathrm{TiO}_{2}$ nanocomposites by deposition of titanium(IV) oxide onto a magnetic core. $\mathrm{TiOSO}_{4}$ was hydrolyzed and precipitated [14]. Another early patented (1997) magnetic photocatalyst was obtained by dispersion of ferromagnetic metal particles in $\mathrm{TiO}_{2}$ suspension [15]. After 1998, others followed depositing photocatalyst onto magnetic core particles [16-19].

Beydoun et al. [20] have shown that contact between crystalline photoactive titanium(IV) oxide and magnetic iron oxide resulted in lower photocatalytic performance with respect to titanium(IV) oxide only for degradation of organic compounds. Interactions between the iron oxide core and the titanium(IV) oxide shell may result in charge carrier recombination of $\mathrm{Fe}_{3} \mathrm{O}_{4}$ during illumination, see Figure 1. Photogenerated electrons elevate to the conduction band (CB) of titanium(IV) oxide, and reduce iron being transferred into the lower conduction band of $\mathrm{Fe}_{3} \mathrm{O}_{4}$ core. The photogenerated holes at the valence band (VB) of $\mathrm{TiO}_{2}$ prefer a more elevated conduction band of the iron oxide core, leading to iron oxidation and subsequent leaching of iron ions into the solution.

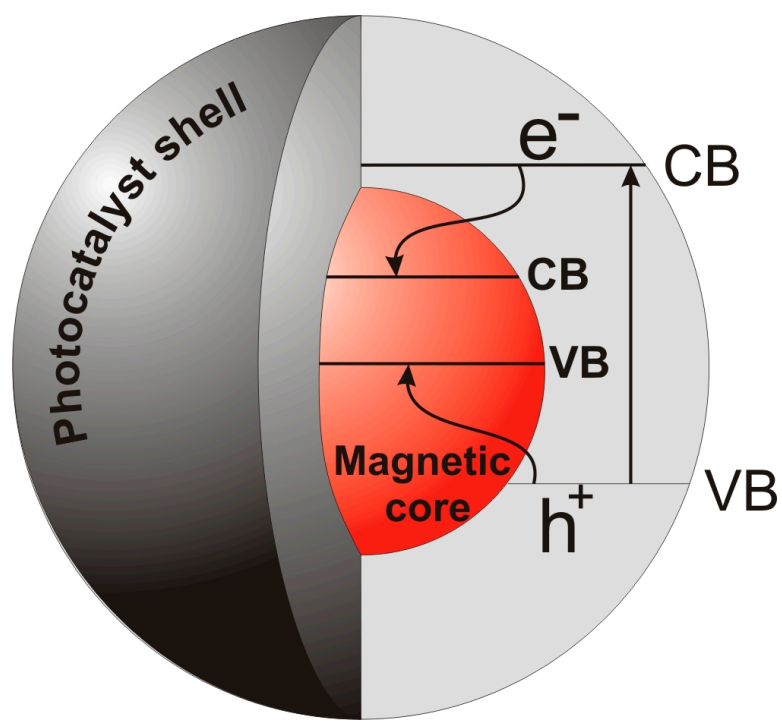

Figure 1. Recombination of charge carriers and photodissolution of $\mathrm{Fe}_{3} \mathrm{O}_{4}$ during irradiation of magnetic core and $\mathrm{TiO}_{2}$ shell photocatalyst.

To overcome photodissolution and protect the magnetic core addition of silica [21,22] or carbon [23], inert layer between the magnetic core and the $\mathrm{TiO}_{2}$ shell was proposed. The structure of the three-component photocatalyst comprises (1) a magnetic core for separation in magnetic field; (2) an interlayer preventing photodissolution and charge carrier recombination; and (3) photocatalytic shell layer for degradation of persistent organic pollutants. Introduction of magnetic nanoparticles into the core/interlayer/shell structure including magnetite [24], maghemite [25], ferrites [26], bimetallic nanoparticles of $\mathrm{Fe}-\mathrm{Ni}$, Co-Fe, Fe-Pt [27], has recently been examined.

In order to provide satisfactory magnetic response and efficient photocatalytic activity for environmental purposes, further research is needed on preparation procedures that will ensure uniform shape and size of magnetic particles as well as their core-interlayer-shell structure.

The aim of this investigation is to better understand the effect of the preparation procedure on adhesion, magnetic properties and photocatalytic activity of $\mathrm{Fe}_{3} \mathrm{O}_{4} / \mathrm{SiO}_{2} / \mathrm{TiO}_{2}, \mathrm{CoFe}_{2} \mathrm{O}_{4} / \mathrm{SiO}_{2} / \mathrm{TiO}_{2}$ and $\mathrm{BaFe}_{12} \mathrm{O}_{19} / \mathrm{SiO}_{2} / \mathrm{TiO}_{2}$ composites in order to ease the separation of the photocatalysts. A novel preparation procedure based on zeta potential analysis in a function of $\mathrm{pH}$ was used. The photocatalytic 
activity was examined through degradation of phenol and carbamazepine as model organic pollutants. The effect of the magnetic core, photocatalytic shellstructure, reaction matrix on the preparation of the three-component magnetic photocatalyst in microemulsion system was investigated.

\section{Results and Discussion}

\subsection{Preparation of Magnetic Photocatalysts-Measurement of Electrophoretic Mobility in a Function of pH (Zeta Potential Determination)}

In water suspension, the surface charge balance is referred to the diffuse layer and it is determined by electrokinetic measurements, such as the zeta potential. It was found that electrostatic forces play important roles in the process of deposition and development of ferrite core, silica interlayer and $\mathrm{TiO}_{2}$ shell structure of the nanocomposites. The relative charges of the surfaces are the determinant parameters indicating whether the interaction is repulsive or attractive during functionalization of the surface (see Figure 2). Values of the isoelectric point (IEP) of particles and substrates indicate the $\mathrm{pH}$, where the zeta potential is equal to zero and the range, where the adhesion is favored. Thus, development of multilayer structure requires the knowledge of the $\mathrm{pH}$ values for ferrite, silica and titania particles.

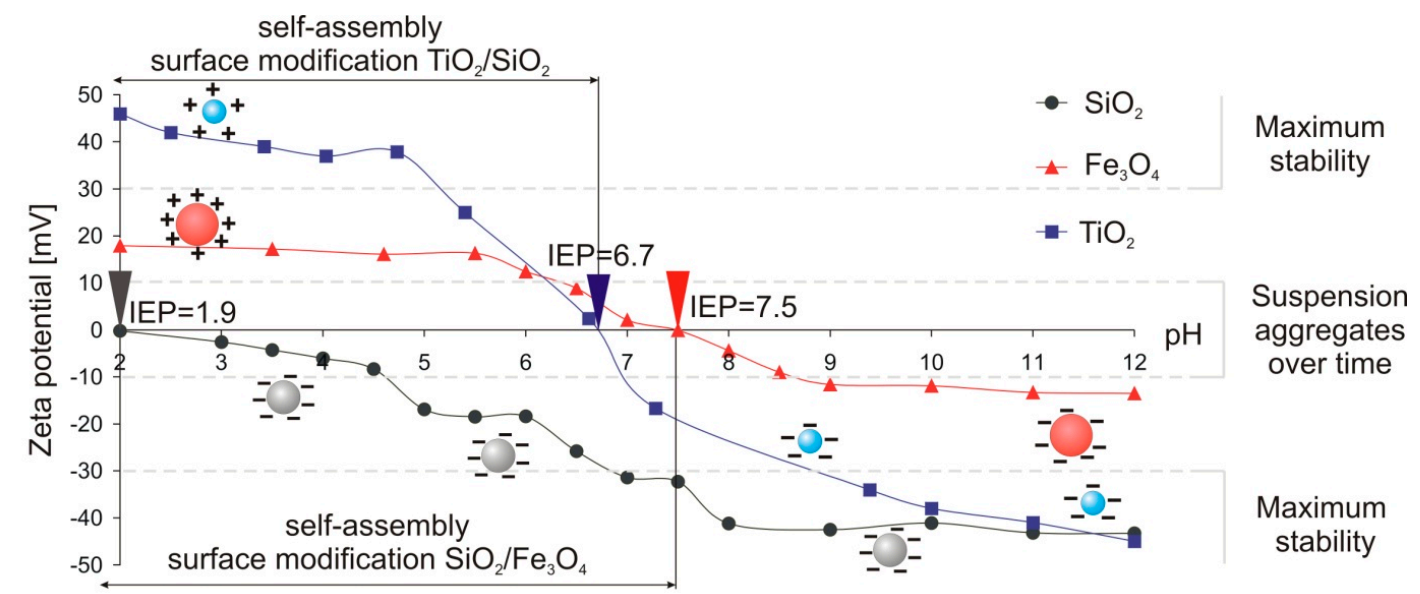

Figure 2. Zeta potential of $\mathrm{Fe}_{3} \mathrm{O}_{4}, \mathrm{SiO}_{2}$ and $\mathrm{TiO}_{2}$ nanoparticles as a function of $\mathrm{pH}$.

Metal oxide, ferrites are amphoteric solids, which in contact with water develop surface charge due to protonation and deprotonation reactions. The amphoteric surface reactions can be described as:

$$
\begin{aligned}
& =\mathrm{FeOH}+\mathrm{H}^{+} \leftrightarrow \mathrm{FeOH}_{2}{ }^{+} \rightarrow \text { acidic solution, } \mathrm{pH}<\mathrm{IEP} \\
& \equiv \mathrm{TiOH}+\mathrm{H}^{+} \leftrightarrow \mathrm{TiOH}_{2}{ }^{+} \rightarrow \text { acidic solution, } \mathrm{pH}<\mathrm{IEP} \\
& =\mathrm{FeOH} \leftrightarrow \mathrm{FeO}^{-}+\mathrm{H}^{+} \rightarrow \text { basic solution, } \mathrm{pH}>\text { IEP } \\
& \equiv \mathrm{TiOH} \leftrightarrow \mathrm{TiO}^{-}+\mathrm{H}^{+} \rightarrow \text { basic solution, } \mathrm{pH}>\text { IEP }
\end{aligned}
$$

From Reactions (1)-(4), the changes of surface charge density as a function of $\mathrm{pH}$ are determined. Below $\mathrm{pH}_{\mathrm{IEC}}$, protonation reaction leads to the formation of $\mathrm{FeOH}_{2}{ }^{+}$and $\mathrm{TiOH}_{2}{ }^{+}$groups, while deprotonation occurs above the isoelectric point and gives rise to $\mathrm{FeO}^{-}$and $\mathrm{TiO}^{-}$groups. The zeta potential of silica particles remained negative between $\mathrm{pH} 2$ and 12 . The zeta potential data (Figures 2 and 3) indicate a positively charged surface of ferrites below pH 6.9 for $\mathrm{CoFe}_{2} \mathrm{O}_{4}$ and 7.5 for $\mathrm{Fe}_{3} \mathrm{O}_{4}$ and $\mathrm{BaFe}_{12} \mathrm{O}_{19}$. For $\mathrm{TiO}_{2}$ particles, the surface was positively charged below $\mathrm{pH} 6.7$ and negatively charged at $\mathrm{pH}$ value above the isoelectric point. 
a)

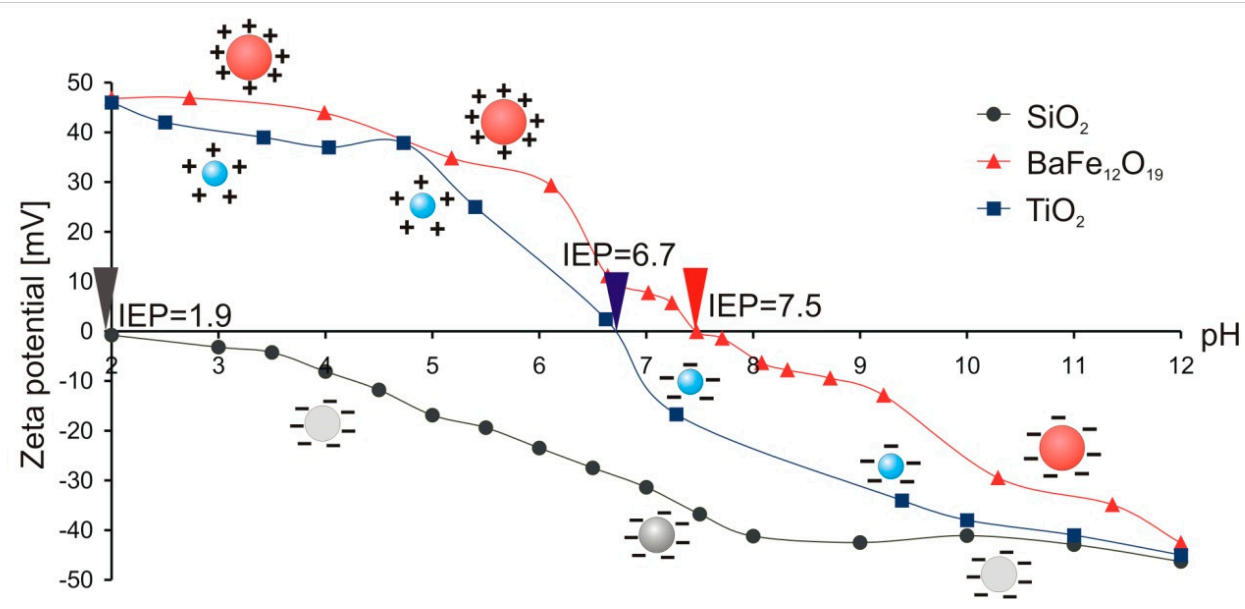

b)

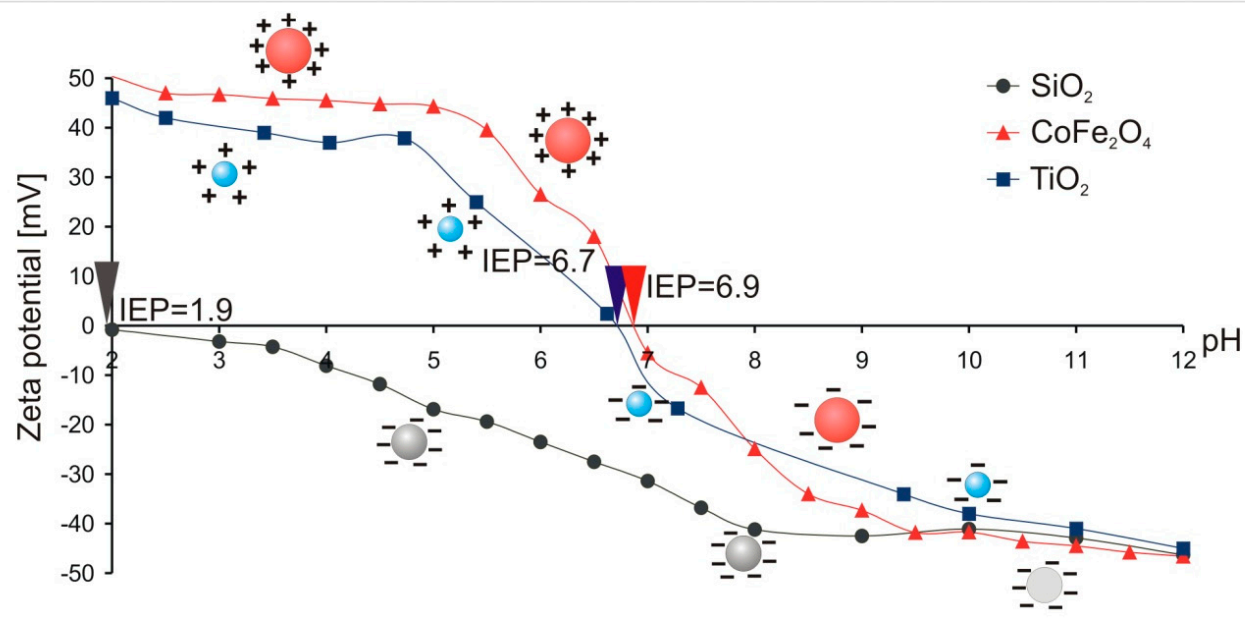

Figure 3. Zeta potential of $\mathrm{CoFe}_{2} \mathrm{O}_{4}(\mathbf{a})$ and $\mathrm{BaFe}_{12} \mathrm{O}_{19}(\mathbf{b})$ determined from the electrophoretic mobility in dependence of the $\mathrm{pH}, \mathrm{I}=1 \times 10^{-4} \mathrm{M} \mathrm{KCl}$.

Since, ferrite particles are positively charged at $\mathrm{pH} 5$, interaction with negatively charged silica leads to self-assembly of $\mathrm{SiO}_{2}$ into the ferrite shell. $\mathrm{TiO}_{2}$ nanoparticles are positively charged at this $\mathrm{pH}$, and therefore, compete with silica particles deposited on the ferrite core. At $\mathrm{pH}$ above 8 , such deposition of silica and titania layers at the magnetite core was unsuccessful. Therefore, the magnetic photocatalyst preparation route was carried out in alkaline conditions by self-assembly of anionic silicates and cationic surfactant molecules cetyltrimethylammonium bromide (CTAB) to form silica shell on ferrite core. The cationic surfactant also effectively interacts with negatively charged titania species in alkaline media, resulting in the core-interlayer-shell structure of nanocomposite.

\subsection{Characterization of the Nanoparticles}

The morphology of the prepared ferrite particles and magnetic photocatalyst is determined by SEM (Figure 4) and TEM (Figure 5) analysis. Crystalline $\mathrm{BaFe}_{12} \mathrm{O}_{19}$ particles hexagonal in shape with random orientation and diameters of the aggregated particles in the range of 40-70 nm were observed. The magnetic $\mathrm{BaFe}_{12} \mathrm{O}_{19}$ core is surrounded by $\mathrm{SiO}_{2}$ and $\mathrm{TiO}_{2}$ layers (Figure $4 \mathrm{~b}$ ). The $\mathrm{CoFe}_{2} \mathrm{O}_{4}$ spherical shape particles coated with $\mathrm{SiO}_{2}$ and $\mathrm{TiO}_{2}$ are visible in Figure 4c. Furthermore, TEM images demonstrate $\mathrm{CoFe}_{2} \mathrm{O}_{4}$ particles composed of primary $15 \mathrm{~nm}$ diameter (Figure $4 \mathrm{~d}$ ), which corresponds well with the $13 \mathrm{~nm}$ crystallite size determined from the XRD pattern using the Scherrer equation. 

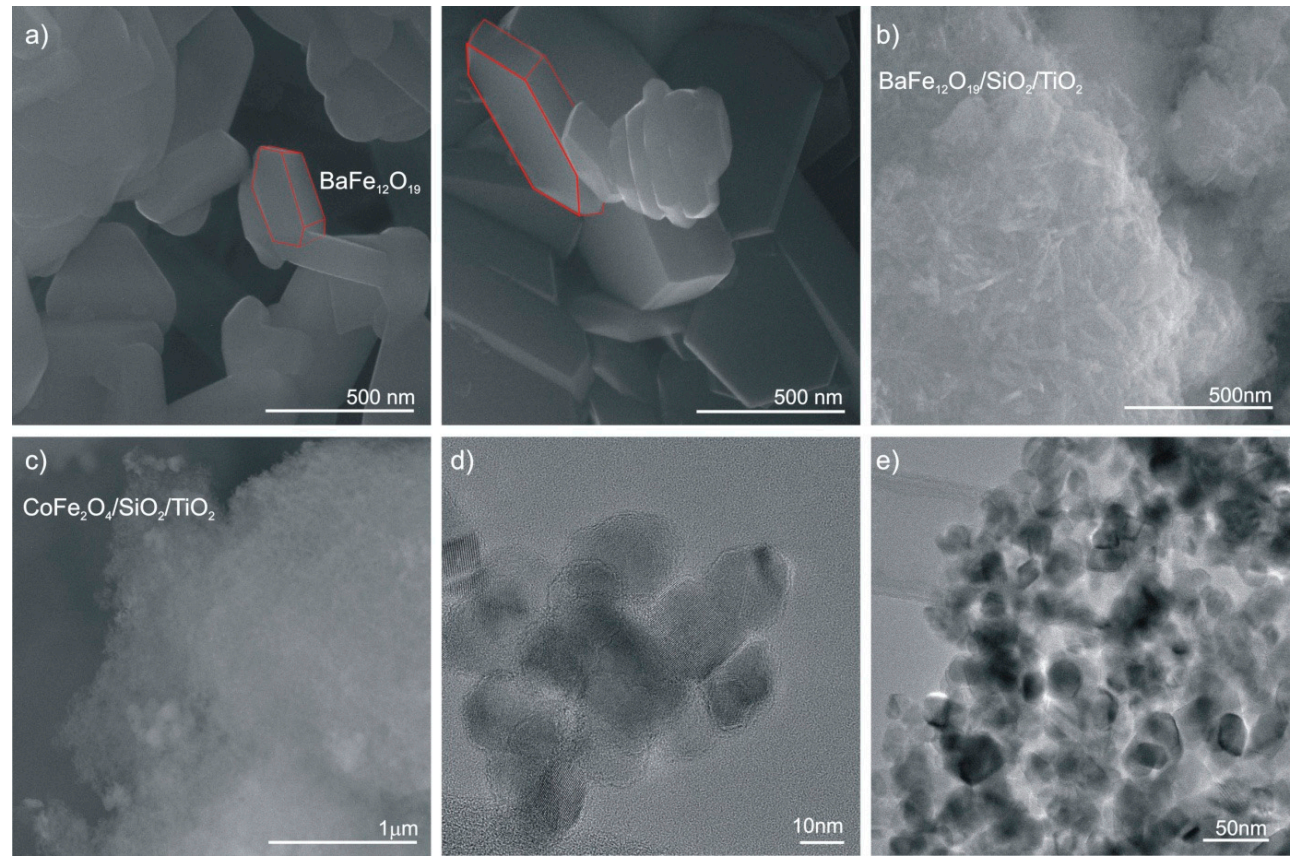

Figure 4. SEM images of barium hexaferrite (a); barium hexaferrite coated with $\mathrm{SiO}_{2}$ and $\mathrm{TiO}_{2}$ layer (b); cobalt ferrite, $\mathrm{CoFe}_{2} \mathrm{O}_{4}$ coated with $\mathrm{SiO}_{2}$ and $\mathrm{TiO}_{2}$ layer (c); TEM images of $\mathrm{CoFe}_{2} \mathrm{O}_{4} / \mathrm{SiO}_{2} / \mathrm{TiO}_{2}$ (d) and $\mathrm{CoFe}_{2} \mathrm{O}_{4} / \mathrm{SiO}_{2} / \mathrm{TiO}_{2}(\mathbf{e})$.

The composition of the core-shell and core-interlayer-shell structure of magnetic nanocomposites was studied using Cs corrected Scanning transmision electron microscopy STEM (high angle annular dark field, HAADF) imaging supplemented with Energy-dispersive X-ray spectroscopy (EDXS) mapping, as shown in Figure 5a,b.
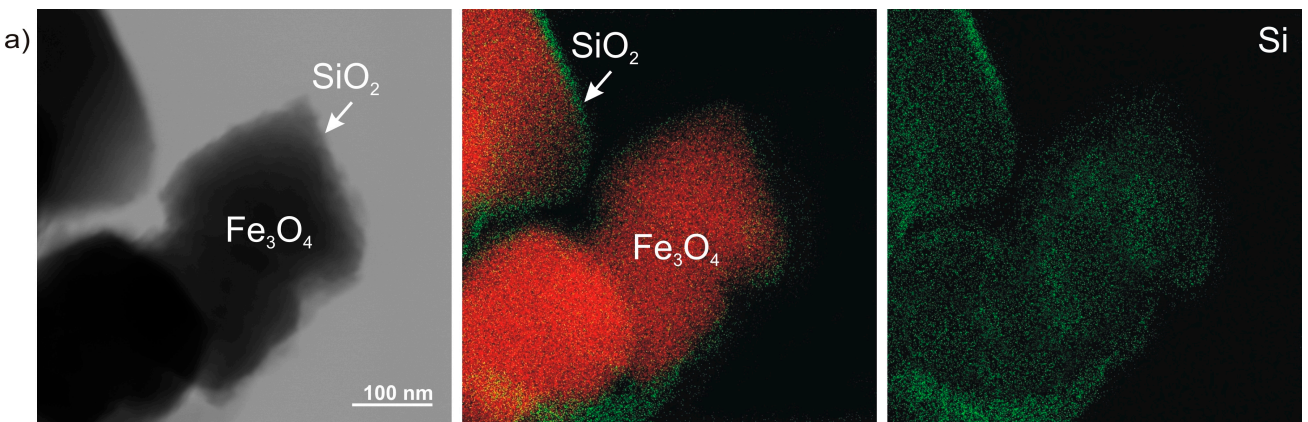

b)
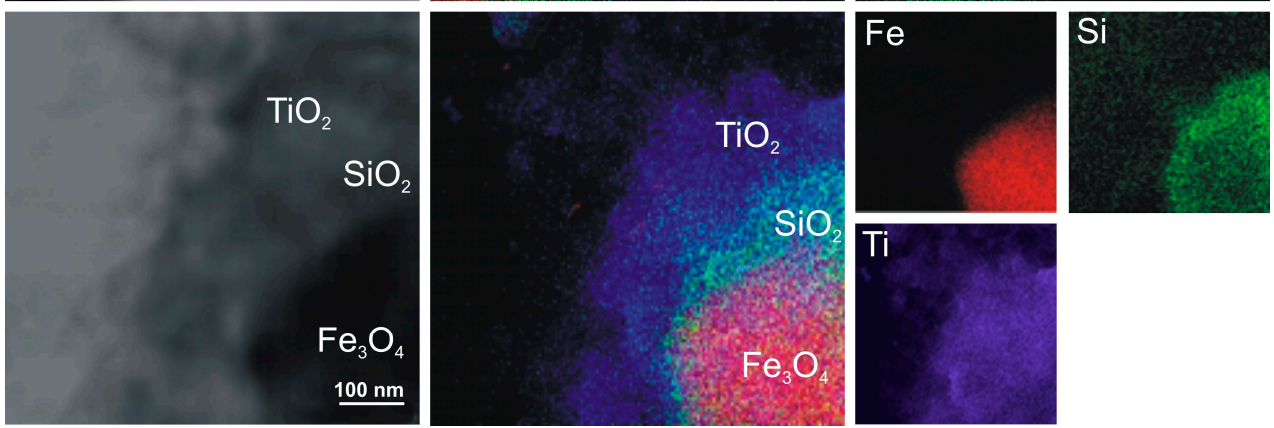

Figure 5. HAADF images of $\mathrm{Fe}_{3} \mathrm{O}_{4} / \mathrm{SiO}_{2}(\mathbf{a})$ and $\mathrm{Fe}_{3} \mathrm{O}_{4} / \mathrm{SiO}_{2} / \mathrm{TiO}_{2}(\mathbf{b})$ combined with mappings of $\mathrm{Fe}_{3} \mathrm{O}_{4}, \mathrm{SiO}_{2}$ and $\mathrm{TiO}_{2}$ (blue is $\mathrm{Ti}$, red is $\mathrm{Fe}$ and green $\mathrm{Si}$ ). 
The single core-shell structure of $\mathrm{Fe}_{3} \mathrm{O}_{4}$ with uniform $\mathrm{SiO}_{2}$ nanometer-thick shell is presented in Figure 5a. According to the TEM image of core-interlayer-shell $\mathrm{Fe}_{3} \mathrm{O}_{4} / \mathrm{SiO}_{2} / \mathrm{TiO}_{2}$ nanoparticle the dark and bright regions correspond to the $\mathrm{Fe}_{3} \mathrm{O}_{4}$ and the shell, respectively. The magnetic core is identified as the darker region compared to the non-magnetic $\mathrm{SiO}_{2}$ and $\mathrm{TiO}_{2}$ shell area due to their different electron-absorbing abilities [28]. The core-interlayer-shell structure of $\mathrm{Fe}_{3} \mathrm{O}_{4}$ coated with $\mathrm{SiO}_{2}$ and $\mathrm{TiO}_{2}$ was confirmed by EDXS mapping, presented in Figure $5 \mathrm{~b}$.

The physicochemical characteristics of the magnetic particles and magnetic photocatalysts e.g., crystallite sizes, indirect band gap values, BET surface areas are given in Table 1 . Cetyltrimethylammonium bromide (CTAB) and t-octylphenoxypolyethoxyethanol (Triton X-100) were used as surfactants. Commercial $\mathrm{TiO}_{2} \mathrm{P} 25$ or $\mathrm{TiO}_{2}$ obtained from titanium butoxide (TBT) hydrolysis were used as starting materials for preparation of photocatalyst layer onto magnetic core. Derived from the plot of the Kubelka-Munk function versus the photon energy gives indirect band gaps of $0.5 \mathrm{eV}, 0.7 \mathrm{eV}, 1.0 \mathrm{eV}$ and $1.4 \mathrm{eV}, 0.9 \mathrm{eV}$ and $1.0 \mathrm{eV}$ for $\mathrm{Fe}_{3} \mathrm{O}_{4}, \mathrm{CoFe}_{2} \mathrm{O}_{4}$, $\mathrm{BaFe}_{12} \mathrm{O}_{19}$ and $\mathrm{Fe}_{3} \mathrm{O}_{4} / \mathrm{SiO}_{2}, \mathrm{CoFe}_{2} \mathrm{O}_{4} / \mathrm{SiO}_{2}, \mathrm{BaFe}_{12} \mathrm{O}_{19} / \mathrm{SiO}_{2}$ particles, respectively. The energy gap of $\mathrm{Fe}_{3} \mathrm{O}_{4} / \mathrm{SiO}_{2} / \mathrm{TiO}_{2}, \mathrm{CoFe}_{2} \mathrm{O}_{4} / \mathrm{SiO}_{2} / \mathrm{TiO}_{2}, \mathrm{BaFe}_{12} \mathrm{O}_{19} / \mathrm{SiO}_{2} / \mathrm{TiO}_{2}$ magnetic photocatalysts were similar to those reported for $\mathrm{TiO}_{2}[29,30]$, which indicates that silica and magnetite particles were not introduce into structure of $\mathrm{TiO}_{2}$.

The BET surface area was evaluated from the nitrogen physisorption data using the Brunauer-EmmettTeller equation [31]. Among ferrite particles, $\mathrm{CoFe}_{2} \mathrm{O}_{4}$ exhibits the smallest crystallite size of $13 \mathrm{~nm}$ and the highest specific surface area of $45 \mathrm{~m}^{2} \cdot \mathrm{g}^{-1}$. The BET surface area increased to $124 \mathrm{~m}^{2} \cdot \mathrm{g}^{-1}$ for $\mathrm{Fe}_{3} \mathrm{O}_{4} / \mathrm{SiO}_{2}$ and $170 \mathrm{~m}^{2} \cdot \mathrm{g}^{-1}$ for $\mathrm{BaFe}_{12} \mathrm{O}_{19} / \mathrm{SiO}_{2}$ nanocomposites. For magnetic photocatalysts, the BET surface area fluctuated from $60 \mathrm{~m}^{2} \cdot \mathrm{g}^{-1}$ to $154 \mathrm{~m}^{2} \cdot \mathrm{g}^{-1}$ and was dependent mainly on the source of $\mathrm{TiO}_{2}$ deposited on ferrite $/ \mathrm{SiO}_{2}$ particles (see in Table 1). The BET surface area for $\mathrm{CoFe}_{2} \mathrm{O}_{4} / \mathrm{SiO}_{2}$ coated with commercial $\mathrm{TiO}_{2} \mathrm{P} 25\left(50 \mathrm{~m}^{2} \cdot \mathrm{g}^{-1}\right)$, was more than two times lower compared to $\mathrm{CoFe}_{2} \mathrm{O}_{4} / \mathrm{SiO}_{2}$ coated with self-obtained $\mathrm{TiO}_{2}$ particles from TBT hydrolysis in water cores of microemulsion with a particle size of $5 \mathrm{~nm}$ and BET area of $178 \mathrm{~m}^{2} \cdot \mathrm{g}^{-1}$. This result further confirms the core-shell structure of magnetic photocatalysts. The ferrite core of nanocomposite was encapsulated with titania, and therefore, the BET surface area of magnetic photocatalyst was related to the surface area of pure $\mathrm{TiO}_{2}$ particles.

Composition of the crystalline phase was examined by XRD analysis with respect to $\mathrm{Fe}_{3} \mathrm{O}_{4}$, $\mathrm{Fe}_{3} \mathrm{O}_{4} / \mathrm{SiO}_{2}, \mathrm{Fe}_{3} \mathrm{O}_{4} / \mathrm{SiO}_{2} / \mathrm{TiO}_{2} 2$ (in Figure 7a) and $\mathrm{CoFe}_{2} \mathrm{O}_{4}, \mathrm{CoFe}_{2} \mathrm{O}_{4} / \mathrm{SiO}_{2}, \mathrm{CoFe}_{2} \mathrm{O}_{4} / \mathrm{SiO}_{2} / \mathrm{TiO}_{2}{ }_{2}$ (in Figure $7 \mathrm{~b}$ ), respectively. The $\mathrm{Fe}_{3} \mathrm{O}_{4}$ nanoparticles exhibit intense peak at $2 \theta=35.2^{\circ}$, which is the (311) reflection and has highly crystalline cubic spinel structure, in agreement with the standard $\mathrm{Fe}_{3} \mathrm{O}_{4}$ XRD spectrum (JCPDS card No. 89-3854).

Table 1. Physicochemical characteristics of the ferrite particles and obtained magnetic photocatalysts.

\begin{tabular}{|c|c|c|c|c|c|c|c|c|}
\hline \multirow{2}{*}{ Sample Label } & \multirow{2}{*}{$\mathrm{TiO}_{2}$ Source } & \multicolumn{2}{|c|}{ Preparation Conditions } & \multicolumn{3}{|c|}{ Crystallite Size (nm) } & \multirow{2}{*}{$\begin{array}{l}\text { BET Surface Area } \\
\left(\mathrm{m}^{2} / \mathrm{g}\right)\end{array}$} & \multirow{2}{*}{$E_{g}(e V)$} \\
\hline & & $\mathrm{pH}$ & Surfactant & Anatase & Rutile & Ferrite & & \\
\hline $\mathrm{Fe}_{3} \mathrm{O}_{4}$ & - & 10 & CTAB & - & - & 45 & 9 & 0.5 \\
\hline $\mathrm{CoFe}_{2} \mathrm{O}_{4}$ & - & 10 & - & - & - & 13 & 45 & 0.7 \\
\hline $\mathrm{BaFe}_{12} \mathrm{O}_{19}$ & - & 10 & СТАВ & - & - & 50 & 0.6 & 1.0 \\
\hline $\mathrm{Fe}_{3} \mathrm{O}_{4} / \mathrm{SiO}_{2}$ & - & 5 & - & - & - & 47 & 169 & 1.4 \\
\hline $\mathrm{CoFe}_{2} \mathrm{O}_{4} / \mathrm{SiO}_{2}$ & - & 5 & - & - & - & 13 & 124 & 0.9 \\
\hline $\mathrm{BaFe}_{12} \mathrm{O}_{19} / \mathrm{SiO}_{2}$ & - & 10 & CTAB & - & - & 50 & 170 & 1.0 \\
\hline $\mathrm{Fe}_{3} \mathrm{O}_{4} / \mathrm{SiO}_{2} / \mathrm{TiO}_{2}{ }_{1}$ & P25 & 5 & TX-100 & 19 & 26 & 47 & 101 & 3.2 \\
\hline $\mathrm{Fe}_{3} \mathrm{O}_{4} / \mathrm{SiO}_{2} / \mathrm{TiO}_{2}{ }_{2}$ & $\mathrm{P} 25$ & 10 & CTAB & 19 & 24 & 45 & 95 & 3.2 \\
\hline $\mathrm{CoFe}_{2} \mathrm{O}_{4} / \mathrm{SiO}_{2} / \mathrm{TiO}_{2} \_1$ & TBT & 5 & TX-100 & 5 & - & 13 & 154 & 3.2 \\
\hline $\mathrm{CoFe}_{2} \mathrm{O}_{4} / \mathrm{SiO}_{2} / \mathrm{TiO}_{2} \_2$ & $\mathrm{P} 25$ & 5 & TX-100 & 18 & 27 & 13 & 69 & 3.2 \\
\hline $\mathrm{BaFe}_{12} \mathrm{O}_{19} / \mathrm{SiO}_{2} / \mathrm{TiO}_{2}{ }_{1}$ & TBT & 10 & CTAB & 5 & - & 50 & 100 & 3.1 \\
\hline $\mathrm{BaFe}_{12} \mathrm{O}_{19} / \mathrm{SiO}_{2} / \mathrm{TiO}_{2} 2$ & TBT & 5 & TX-100 & 5 & - & 49 & 60 & 3.1 \\
\hline
\end{tabular}

Moreover, for cobalt ferrite particles, the diffraction peak positions attributed to (220), (311), (400) and (440) reflections also confirmed formation of cubic spine phase, which is in accordance with JCPDS card No. 22-1086. The broad diffraction peak at $2 \theta=15-25^{\circ}$ corresponds to an amorphous silica layer in the nanocomposite structure $[32,33]$. The diffraction peaks of $\mathrm{TiO}_{2}$ can be attributed to 
(101), (103), (200) and (105) reflections of anatase $\mathrm{TiO}_{2}$, and (110), (101), (200) reflections of rutile $\mathrm{TiO}_{2}$ and are in agreement with the standard anatase XRD spectrum (JCPDS card No. 89-4203) and rutile XRD spectrum (JCPDS, No. 76-1940). The most intense diffraction peaks of spinel ferrite particles in the XRD patterns (Figure $7 \mathrm{a}, \mathrm{b}$ ) at $35.3^{\circ}$ for $\mathrm{Fe}_{3} \mathrm{O}_{4}$ and $31.8^{\circ}$ for $\mathrm{CoFe}_{2} \mathrm{O}_{4}$ became weaker, due to the formation of the $\mathrm{TiO}_{2}$ shell on the surface of ferrite particles.

The magnetic properties of uncoated and coated ferrite nanocomposites were investigated using magnetic hysteresis curves from ACMS analysis at room temperature as shown in Figure 6. The magnetic parameters, such as saturation magnetization $\left(M_{s}\right)$, coercivity $\left(H_{c}\right)$ and remanent magnetization $\left(M_{r}\right)$ are given in Table 2. Obtained spinel and hexagonal ferrites posse strong ferromagnetic properties. The saturation magnetization $\left(M_{s}\right)$ of $\mathrm{Fe}_{3} \mathrm{O}_{4}, \mathrm{BaFe}_{12} \mathrm{O}_{19}$ and $\mathrm{CoFe}_{2} \mathrm{O}_{4}$ were $89 \mathrm{emu} / \mathrm{g}, 64 \mathrm{emu} / \mathrm{g}$ and $39 \mathrm{emu} / \mathrm{g}$, respectively.

Table 2. Magnetic parameters of the uncoated and coated ferrite nanoparticles.

\begin{tabular}{|c|c|c|c|}
\hline Sample Label & $M_{s}\left(\mathrm{emu} \cdot \mathrm{g}^{-1}\right)$ & $H_{c}(\mathrm{Oe})$ & $M_{r}\left(\mathrm{emu} \cdot \mathrm{g}^{-1}\right)$ \\
\hline $\mathrm{Fe}_{3} \mathrm{O}_{4}$ & 89 & 100 & 9 \\
\hline $\mathrm{CoFe}_{2} \mathrm{O}_{4}$ & 60 & 130 & 2 \\
\hline $\mathrm{BaFe}_{12} \mathrm{O}_{19}$ & 64 & 140 & 16 \\
\hline $\mathrm{Fe}_{3} \mathrm{O}_{4} / \mathrm{SiO}_{2}$ & 17 & 100 & 2 \\
\hline $\mathrm{CoFe}_{2} \mathrm{O}_{4} / \mathrm{SiO}_{2}$ & 15 & 150 & 0 \\
\hline $\mathrm{BaFe}_{12} \mathrm{O}_{19} / \mathrm{SiO}_{2}$ & 46 & 80 & 4 \\
\hline $\mathrm{Fe}_{3} \mathrm{O}_{4} / \mathrm{SiO}_{2} / \mathrm{TiO}_{2} \_1$ & 8 & 100 & 1 \\
\hline $\mathrm{Fe}_{3} \mathrm{O}_{4} / \mathrm{SiO}_{2} / \mathrm{TiO}_{2} \_2$ & 7 & 100 & 1 \\
\hline $\mathrm{CoFe}_{2} \mathrm{O}_{4} / \mathrm{SiO}_{2} / \mathrm{TiO}_{2} \_1$ & 9 & 250 & 1 \\
\hline $\mathrm{CoFe}_{2} \mathrm{O}_{4} / \mathrm{SiO}_{2} / \mathrm{TiO}_{2 \_} 2$ & 6 & 150 & 1 \\
\hline $\mathrm{BaFe}_{12} \mathrm{O}_{19} / \mathrm{SiO}_{2} / \mathrm{TiO}_{2}{ }_{1}$ & 43 & 80 & 9 \\
\hline $\mathrm{BaFe}_{12} \mathrm{O}_{19} / \mathrm{SiO}_{2} / \mathrm{TiO}_{2 \_} 2$ & 33 & 80 & 9 \\
\hline
\end{tabular}

The magnetic properties of materials are influenced by particles size, crystallinity and surface structure. The $M_{S}$ of the ferrite $/ \mathrm{SiO}_{2}$ and ferrite $/ \mathrm{SiO}_{2} / \mathrm{TiO}_{2}$ nanocomposites decreases after coating with silica and titania layers, while the coercivity of titania-silica-coated $\mathrm{Fe}_{3} \mathrm{O}_{4}, \mathrm{BaFe}_{12} \mathrm{O}_{19}$ and $\mathrm{CoFe}_{2} \mathrm{O}_{4}$ nanoparticles does not show any change after coating, because coercivity represents the property of magnetic material and is determined by the strength and number of the magnetic dipole in the magnetic domain [34]. Furthermore, saturation magnetization values for $\mathrm{Fe}_{3} \mathrm{O}_{4}$ nanocomposites were recalculated using emu/mol of $\mathrm{Fe}_{3} \mathrm{O}_{4}$, see in Figure 6d. The amount of ferrite particles was determined from $\mathrm{X}$-ray fluorescence spectrometer (XRF) analysis and these results were in agreement with theoretical stoichiometric calculations. The hysteresis loops do not change after coating. There is a $14 \%$ difference of $M_{s}$ between uncoated $\mathrm{Fe}_{3} \mathrm{O}_{4}(3372 \mathrm{emu} / \mathrm{mol})$ and $\mathrm{Fe}_{3} \mathrm{O}_{4}$ coated with $\mathrm{SiO}_{2}$ or $\mathrm{SiO}_{2} / \mathrm{TiO}_{2}$ layer $(2919 \mathrm{emu} / \mathrm{mol})$. 
a)

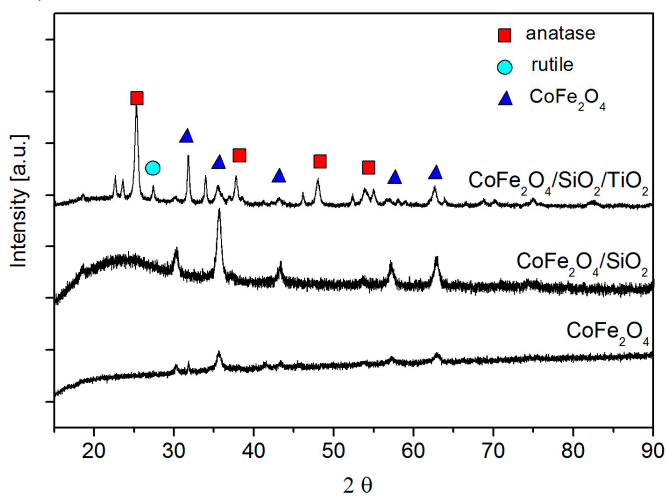

b)

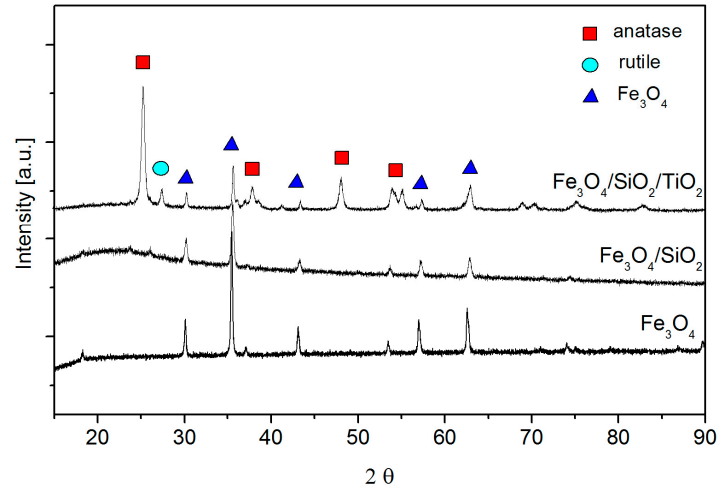

Figure 6. X-ray diffraction patterns of the as-prepared $\mathrm{Fe}_{3} \mathrm{O}_{4}, \mathrm{Fe}_{3} \mathrm{O}_{4} / \mathrm{SiO}_{2}, \mathrm{Fe}_{3} \mathrm{O}_{4} / \mathrm{SiO}_{2} / \mathrm{TiO}_{2} 2$ (a) and $\mathrm{CoFe}_{2} \mathrm{O}_{4}, \mathrm{CoFe}_{2} \mathrm{O}_{4} / \mathrm{SiO}_{2}, \mathrm{CoFe}_{2} \mathrm{O}_{4} / \mathrm{SiO}_{2} / \mathrm{TiO}_{2} 2$ 2 (b).

a)
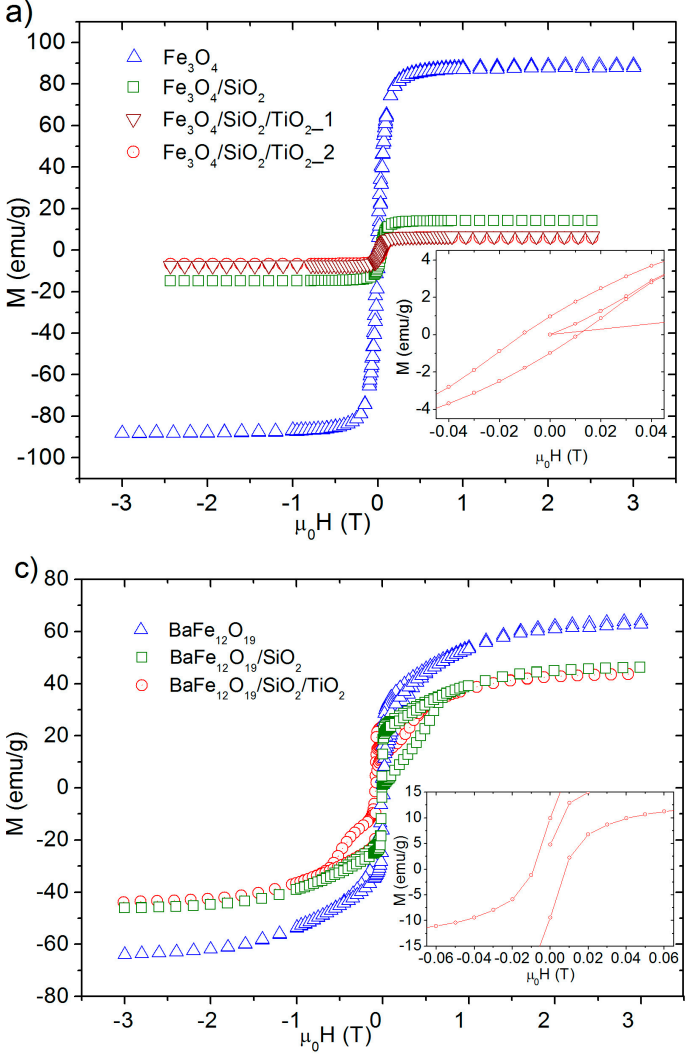
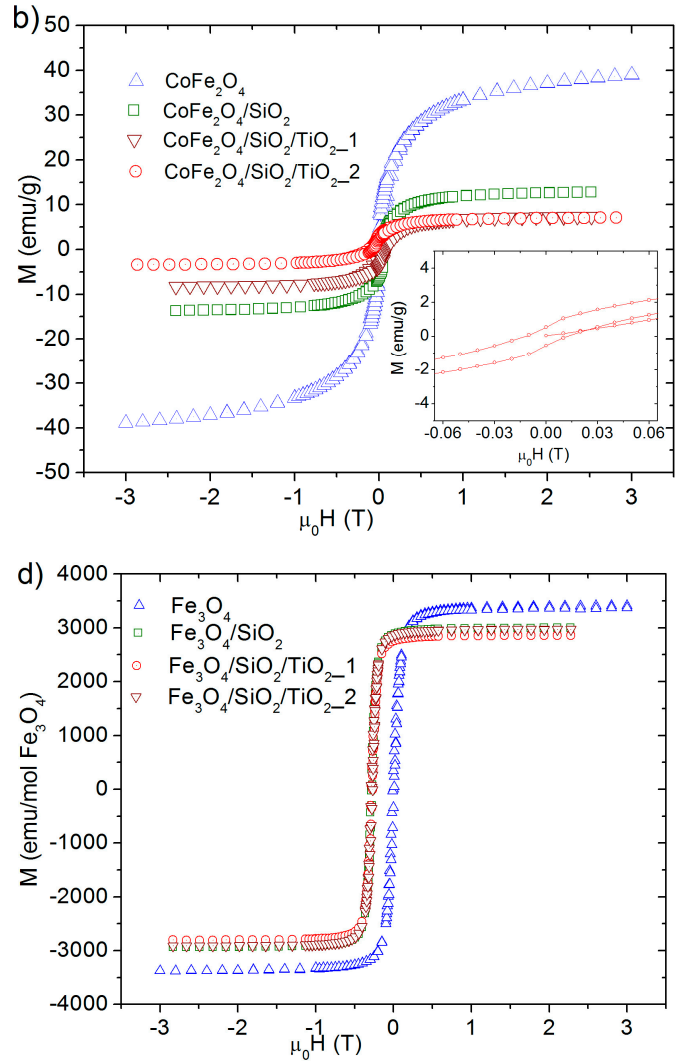

Figure 7. Magnetic hysteresis loops of $\mathrm{Fe}_{3} \mathrm{O}_{4}$ based nanocomposites (a); $\mathrm{CoFe}_{2} \mathrm{O}_{4}$-based nanocomposites (b) and $\mathrm{BaFe}_{12} \mathrm{O}_{19}$-based nanoparticles (c); recalculated hysteresis loops for $\mathrm{Fe}_{3} \mathrm{O}_{4}$ composites (d).

The magnetic photocatalysts can exhibit superparamagnetic behavior due to their small $H_{\mathcal{C}}$ and $M_{r}$ values.

The critical sizes of the magnetic single-domain were calculated using equation:

$$
D_{c r}=5.1 \sqrt{\frac{A}{\mu_{0} M_{S}^{2}}}
$$

where $A$ is the exchange stiffness and $M_{S}$ is the saturation magnetization of the material and the data are given in Table 3. The critical size of a magnetic single-domain calculated for $\mathrm{Fe}_{3} \mathrm{O}_{4}$ with $M_{S}$ value 
of $89 \mathrm{emu} / \mathrm{g}$, using exchange stiffness $A=0.7 \mu \mathrm{erg} / \mathrm{cm}(7 \mathrm{pJ} / \mathrm{m})$ [35] was about $250 \mathrm{~nm}$. This value exceeds the limit of the critical radius for superparamagnetic domain of $\mathrm{Fe}_{3} \mathrm{O}_{4}$, which is about $49 \mathrm{~nm}$ [36]. On the other hand, the single-domain critical sizes $\left(D_{c r}\right)$ were $67.5 \mathrm{~nm}$ and $24.8 \mathrm{~nm}$ for $\mathrm{BaFe}_{12} \mathrm{O}_{19}$ and $\mathrm{CoFe}_{2} \mathrm{O}_{4}$ and were lower than theoretical values [37,38], suggesting that the obtained $\mathrm{BaFe}_{12} \mathrm{O}_{19}$ and $\mathrm{CoFe}_{2} \mathrm{O}_{4}$ magnetic nanocomposites can reveal superparamagnetic properties.

Table 3. Critical sizes of single-domain magnetic $\mathrm{Fe}_{3} \mathrm{O}_{4}, \mathrm{BaFe}_{12} \mathrm{O}_{19}, \mathrm{CoFe}_{2} \mathrm{O}_{4}$ nanoparticles.

\begin{tabular}{ccccccc}
\hline & $\begin{array}{c}\boldsymbol{M}_{\boldsymbol{s}} \\
(\mathbf{e m u} / \mathbf{g})\end{array}$ & $\begin{array}{c}\boldsymbol{A} \\
(\mathbf{p J} / \mathbf{m})\end{array}$ & $\begin{array}{c}\boldsymbol{D}_{\boldsymbol{c r}} \\
(\mathbf{n m})\end{array}$ & $\begin{array}{c}\text { Literature } \boldsymbol{D}_{\boldsymbol{c r}} \\
(\mathbf{n m})\end{array}$ & $\begin{array}{c}\mathbf{d} \\
(\mathbf{n m})\end{array}$ & Refs. \\
\hline $\mathrm{Fe}_{3} \mathrm{O}_{4}$ & 89 & 7 & 250 & 49 & $>200$ & {$[36]$} \\
$\mathrm{BaFe}_{12} \mathrm{O}_{19}$ & 60 & 20 & 67.5 & 1000 & 70 & {$[37]$} \\
$\mathrm{CoFe}_{2} \mathrm{O}_{4}$ & 64 & 3 & 24.8 & 30 & 15 & {$[38]$} \\
\hline
\end{tabular}

Furthermore, when the applied intensity of magnetic field is close to zero, the remnant magnetization of samples decreases to zero. It indicates that the samples can be separated from water when an external magnetic field is added, and redispersed in water solution after the external magnetic field is eliminated, as shown in Figure 8, for $\mathrm{CoFe}_{2} \mathrm{O}_{4} / \mathrm{SiO}_{2} / \mathrm{TiO}_{2}$ nanocomposite.
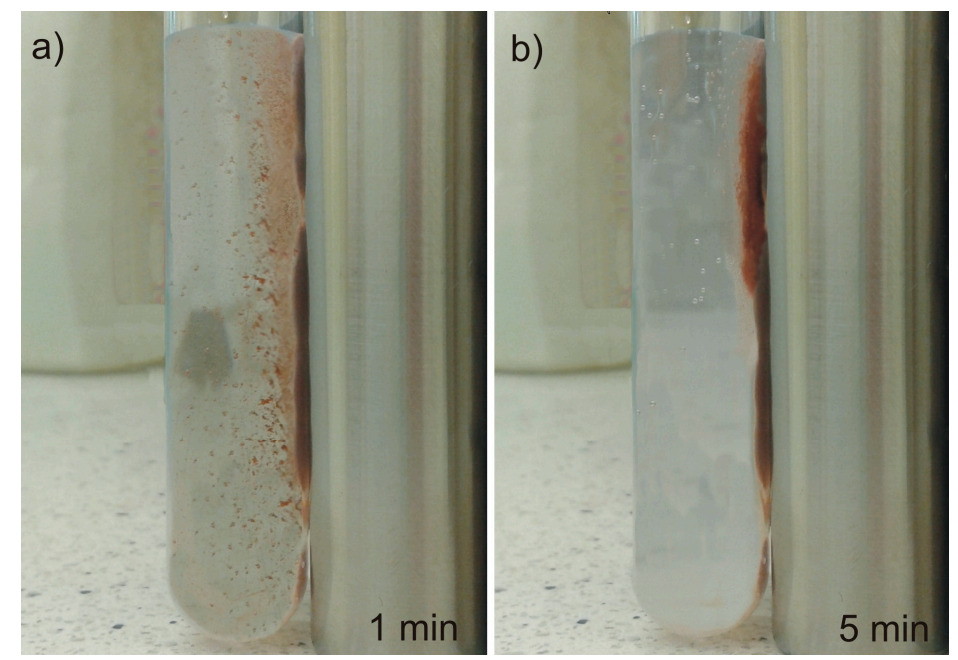

Figure 8. Image of $\mathrm{CoFe}_{2} \mathrm{O}_{4} / \mathrm{SiO}_{2} / \mathrm{TiO}_{2}$ magnetic separation after $1 \mathrm{~min}(\mathbf{a})$ and $5 \mathrm{~min}(\mathbf{b})$ after applying magnet rod.

\subsection{Photocatalytic Activity of Magnetic Nanocomposites}

In the first round of experiments of our study, phenol was selected as a model pollutant. Phenol and its derivatives are commonly encountered organic pollutants in industrial effluents that have caused severe environmental problems. Phenol was not degraded in the absence of illumination, indicating that there was no dark reaction at the surface of self-prepared nanocomposites. The functionalization of the magnetic core with silica interlayer and a layer of commercial $\mathrm{TiO}_{2}$ P25 results in higher photocatalytic performance, as shown in Figure 9 for $\mathrm{Fe}_{3} \mathrm{O}_{4} / \mathrm{SiO}_{2} / \mathrm{TiO}_{2}{ }_{1}$, $\mathrm{Fe}_{3} \mathrm{O}_{4} / \mathrm{SiO}_{2} / \mathrm{TiO}_{2} 2$ and $\mathrm{CoFe}_{2} \mathrm{O}_{4} / \mathrm{SiO}_{2} / \mathrm{TiO}_{2} \_$photocatalysts.

Moreover, phenol degradation for $\mathrm{Fe}_{3} \mathrm{O}_{4} / \mathrm{SiO}_{2} / \mathrm{TiO}_{2}$ and $\mathrm{CoFe}_{2} \mathrm{O}_{4} / \mathrm{SiO}_{2} / \mathrm{TiO}_{2} 2$ nanocomposites was comparable to the commercial nano-sized $\mathrm{TiO}_{2} \mathrm{P} 25$ (Evonik, Essen, Germany), which proves effective deposition of $\mathrm{TiO}_{2} \mathrm{P} 25$ onto the magnetic core with the ability to easily separation of photocatalyst from reaction system. Total organic carbon (TOC) analysis also revealed that high mineralization was achieved for $\mathrm{Fe}_{3} \mathrm{O}_{4} / \mathrm{SiO}_{2} / \mathrm{TiO}_{2} 1, \mathrm{CoFe}_{2} \mathrm{O}_{4} / \mathrm{SiO}_{2} / \mathrm{TiO}_{2} 2$ and $\mathrm{Fe}_{3} \mathrm{O}_{4} / \mathrm{SiO}_{2} / \mathrm{TiO}_{2} 2$. After $30 \mathrm{~min}$. of irradiation more than $90 \%$ of phenol was decomposed and mineralization was above 
$80 \%$. The magnetic photocatalysts $\mathrm{CoFe}_{2} \mathrm{O}_{4} / \mathrm{SiO}_{2} / \mathrm{TiO}_{2} \_1$ and $\mathrm{BaFe}_{12} \mathrm{O}_{19} / \mathrm{SiO}_{2} / \mathrm{TiO}_{2 \_} 2$ obtained by deposition of $\mathrm{TiO}_{2}$ from TBT hydrolysis in water cores of microemulsion revealed lower photocatalytic activity in reactions of phenol degradation. After $30 \mathrm{~min}$. of irradiation about $80 \%$ and $27 \%$ of phenol was degraded and mineralization was $52 \%$ and $15 \%$ for $\mathrm{CoFe}_{2} \mathrm{O}_{4} / \mathrm{SiO}_{2} / \mathrm{TiO}_{2} \_1$ and $\mathrm{BaFe}_{12} \mathrm{O}_{19} / \mathrm{SiO}_{2} / \mathrm{TiO}_{2} \_$, respectively. Salamat et al. reported that the variations in the photocatalytic activity of $\mathrm{TiO}_{2} / \mathrm{SiO}_{2}$ deposited on $\mathrm{Fe}_{3} \mathrm{O}_{4}$ are probably related to the effect of change in the molar ratio of $\mathrm{Ti}$ and $\mathrm{Si}$ to $\mathrm{Fe}_{3} \mathrm{O}_{4}$ [28]. Therefore, it can be assumed that photocatalytic and magnetic properties can be manufactured by appropriately adjusting the reaction condition during formation of the semiconductor shell. That means adjustment of a ratio of the core portion particle diameter and shell thickness depends on appropriately adjusting the formation condition during formation of the shell. Further study on the selection and setting of the specific conditions with respect to individual magnetic particles are presently being conducted.

Another set of experiments were performed using carbamazepine as a model organic compound. Carbamazepine is one of the commonly used pharmaceuticals, which passes through wastewater treatment plants almost completely unaffected and has been found to be highly persistent in the environment. The efficiency of carbamazepine degradation is presented in Figure 10 and described as TOC removal fraction.

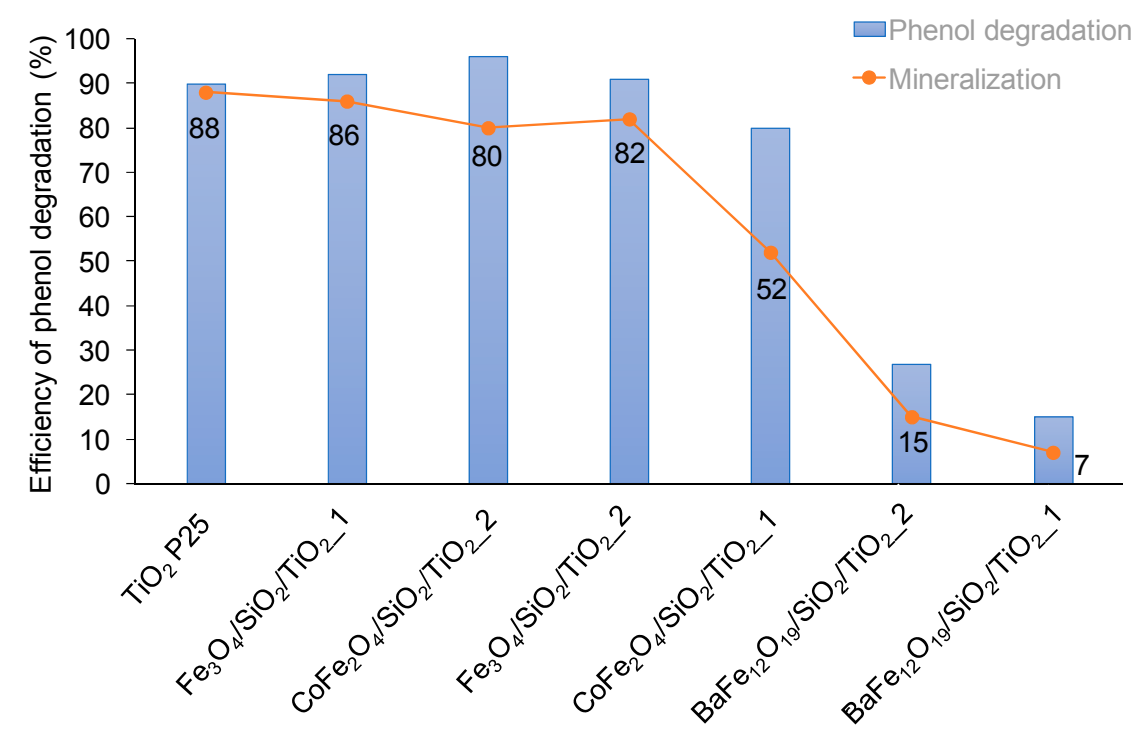

Figure 9. Efficiency of phenol degradation $(\mathrm{C} / \mathrm{Co})$ and mineralization (TOC/TOCo) of obtained magnetic photocatalysts. 


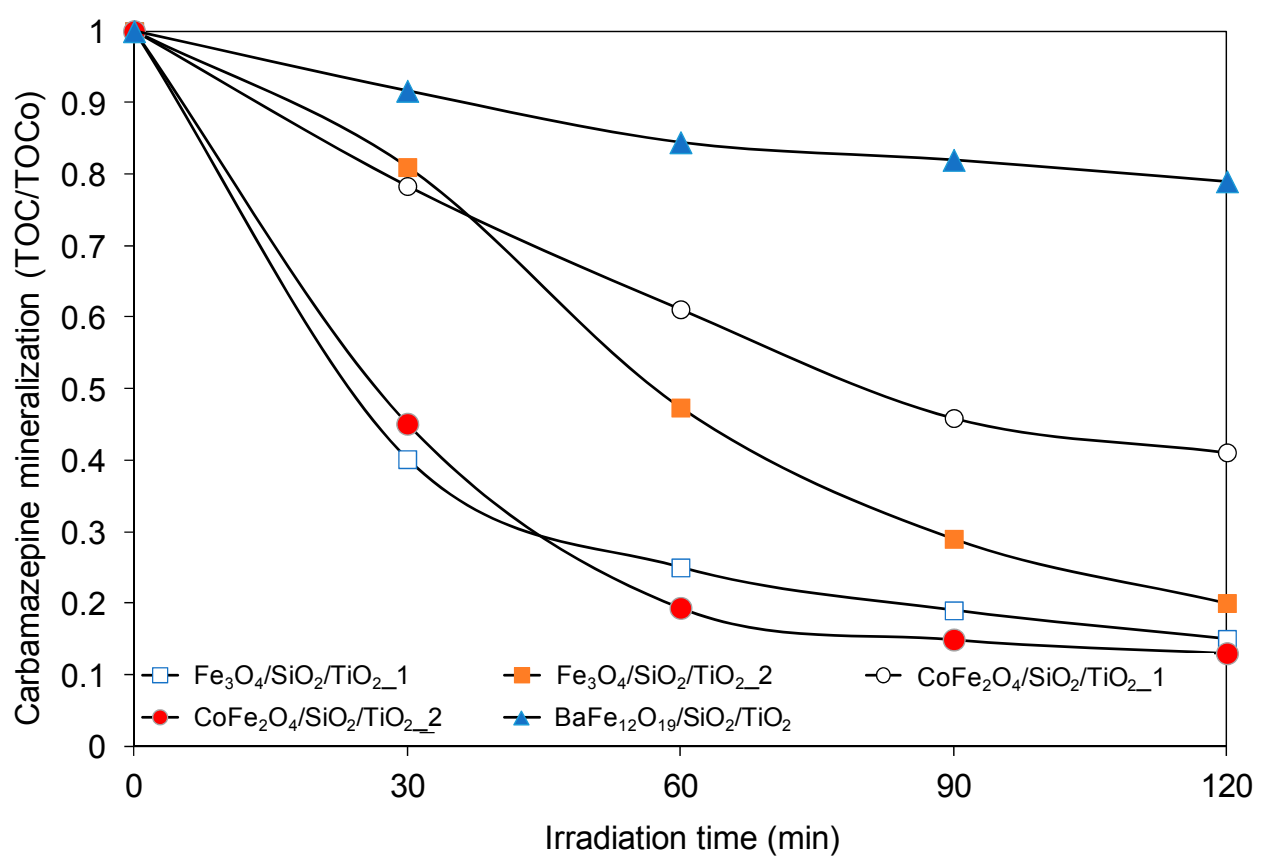

Figure 10. Photomineralization of carbamazepine measured as TOC removal as a function of reaction time. Experimental conditions: phenol initial concentration $\mathrm{Co}=6 \times 10^{-5} \mathrm{M}$, content of photocatalyst $2 \mathrm{~g} \cdot \mathrm{dm}^{-3}, 300 \mathrm{~W}$ xenon lamp.

The highest efficiency of carbamazepine mineralization revealed $\mathrm{CoFe}_{2} \mathrm{O}_{4} / \mathrm{SiO}_{2} / \mathrm{TiO}_{2} 2$ and $\mathrm{Fe}_{3} \mathrm{O}_{4} / \mathrm{SiO}_{2} / \mathrm{TiO}_{2} \_1$ magnetic photocatalysts, which were also the most active in reaction of phenol degradation. After 120 min. of irradiation, TOC removal was $87 \%$ and $85 \%$ for $\mathrm{CoFe}_{2} \mathrm{O}_{4} / \mathrm{SiO}_{2} / \mathrm{TiO}_{2}{ }_{2}$ and $\mathrm{Fe}_{3} \mathrm{O}_{4} / \mathrm{SiO}_{2} / \mathrm{TiO}_{2} \_1$, respectively. For $\mathrm{CoFe}_{2} \mathrm{O}_{4} / \mathrm{SiO}_{2} / \mathrm{TiO}_{2} \_1, \mathrm{Fe}_{3} \mathrm{O}_{4} / \mathrm{SiO}_{2} / \mathrm{TiO}_{2} \_2$ and $\mathrm{BaFe}_{12} \mathrm{O}_{19} / \mathrm{SiO}_{2} / \mathrm{TiO}_{2} \_2$ nanocomposites the carbamazepine removal efficiency equaled $54 \%$, $80 \%$ and $21 \%$, respectively.

Furthermore, the most active magnetic photocatalyst $\mathrm{CoFe}_{2} \mathrm{O}_{4} / \mathrm{SiO}_{2} / \mathrm{TiO}_{2} 2$ was selected for reusability studies. In order to evaluate the effectiveness of magnetic photocatalyst after its recovery, the four subsequent cycles were carried out, see data in Figure 11. At the end of the first run of phenol degradation, $\mathrm{CoFe}_{2} \mathrm{O}_{4} / \mathrm{SiO}_{2} / \mathrm{TiO}_{2} 2$ nanoparticles were separated from aqueous solution by external magnetic field and then treated wastewater was discharged. The separated photocatalyst was then reused without any treatment. High photocatalytic degradation was maintained after four consecutive cycles, without any loss in degradation. 


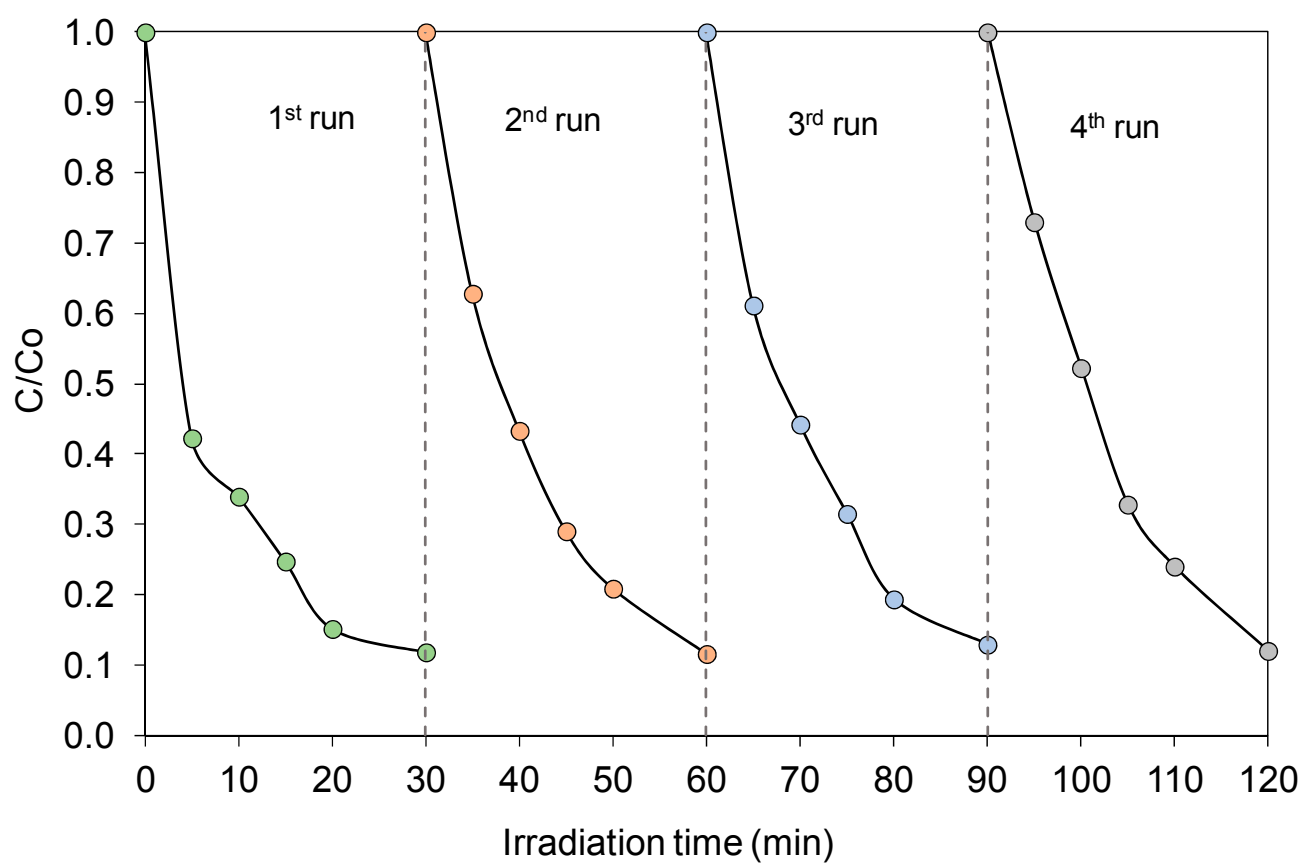

Figure 11. Efficiency of phenol degradation in the presence of $\mathrm{CoFe}_{2} \mathrm{O}_{4} / \mathrm{SiO}_{2} / \mathrm{TiO}_{2}$ magnetic photocatalyst measured in the fourth subsequent cycles.

\subsection{Discussion}

Core-interlayer-shell structure magnetic photocatalysts were prepared in a w/o microemulsion system based on changes in the zeta potential as a function of $\mathrm{pH}$. Ferrite particles are positively charged in acidic medium $(\mathrm{pH}<7)$, while silica nanoparticles showed negative charge in the $\mathrm{pH}$ range of 2-12. Therefore, the functionalization of magnetic core with silica interlayer in acidic medium leads to self-assembly of $\mathrm{SiO}_{2}$ into the ferrite shell. Electrostatic interactions between negatively charged silica and positively charged titania particles enables the functionalization of magnetic core with silica interlayer and $\mathrm{TiO}_{2}$ photocatalyst layer in acidic conditions. At $\mathrm{pH}$ above 7 , such deposition of silica and titania layers at the magnetite core was unsuccessful. Therefore, magnetic photocatalyst preparation route was carried out in alkaline conditions by self-assembly of anionic silicates and cationic surfactant molecules (CTAB) to form a silica shell on a ferrite core. The cationic surfactant also effectively interacts with negatively charged titania species in alkaline media, resulting in the core-interlayer-shell structure of nanocomposites. The energy gap of the core-interlayer-shell magnetic photocatalysts was similar to those reported for $\mathrm{TiO}_{2}$. Moreover, the ferrite core encapsulated with silica and titania exhibited the BET surface area related to surface area of pure $\mathrm{TiO}_{2}$ particles, which indicates that the ferrite core was encapsulated with titania shell, and therefore, the BET surface area of magnetic photocatalyst was related to pure $\mathrm{TiO}_{2}$ particles surface area. Furthermore, the composition of the core-shell and core-interlayer-shell structure of magnetic nanocomposites was confirmed by TEM microscopy with EDXS mapping. The $\mathrm{CoFe}_{2} \mathrm{O}_{4}$ core coated with silica interlayer and $\mathrm{TiO}_{2} \mathrm{P} 25$ layer exhibited long-term photocatalytic activity, in which more than $80 \%$ of phenol is decomposed to $\mathrm{CO}_{2}$ in each 30-min cycle of degradation.

Higher photocatalytic activity was observed for the samples $\mathrm{Fe}_{3} \mathrm{O}_{4} / \mathrm{SiO}_{2} / \mathrm{TiO}_{2}{ }_{1}$, $\mathrm{CoFe}_{2} \mathrm{O}_{4} / \mathrm{SiO}_{2} / \mathrm{TiO}_{2} \_2$ and $\mathrm{Fe}_{3} \mathrm{O}_{4} / \mathrm{SiO}_{2} / \mathrm{TiO}_{2} \_2$ obtained by deposition of commercial $\mathrm{TiO}_{2}$ $\mathrm{P} 25$ on the ferrite core and silica shell nanoparticles with respect to the magnetic photocatalysts $\mathrm{CoFe}_{2} \mathrm{O}_{4} / \mathrm{SiO}_{2} / \mathrm{TiO}_{2}{ }_{1}$ and $\mathrm{BaFe}_{12} \mathrm{O}_{19} / \mathrm{SiO}_{2} / \mathrm{TiO}_{2} 2$ obtained by deposition of $\mathrm{TiO}_{2}$ from TBT hydrolysis. The titanium(IV) oxide P25 consisting of mixture of anatase and rutile phases is a well-known and widely investigated photocatalyst used as reference material to evaluate the photocatalytic activity of new materials. The higher photocatalytic activity of $\mathrm{TiO}_{2} \mathrm{P} 25$ 
compared to anatase is ascribed to synergistic effects of anatase and rutile particles, which enhance the electron-hole separation $[39,40]$. Recent studies have shown that photoactivity of P25 exceeds that of anatase in several reaction systems [41,42]. Previously, we have also reported that $\mathrm{TiO}_{2} \mathrm{P} 25$, which is a mixture of anatase and rutile phases exhibited higher efficiency of phenol, pyridine and 4-heptanone degradation compared to commercial anatase particles $\mathrm{TiO}_{2}$ ST-01 and anatase obtained from titanium isopropoxide (TIP) and titanium butoxide (TBT) hydrolysis in aqueous phase [43,44]. Therefore, the lower photocatalytic activity of $\mathrm{BaFe}_{12} \mathrm{O}_{19} / \mathrm{SiO}_{2} / \mathrm{TiO}_{2} 2$ nanocomposite results from the properties of the photocatalytic layer instead of the magnetic core behavior. Salamat et al. [28] reported that the variations in the photocatalytic activity of $\mathrm{TiO}_{2} / \mathrm{SiO}_{2}$ deposited on $\mathrm{Fe}_{3} \mathrm{O}_{4}$ are related to the effect of change in the molar ratio of $\mathrm{Ti}$ and $\mathrm{Si}$ to $\mathrm{Fe}_{3} \mathrm{O}_{4}$. Therefore, it can be assumed that the amount of silica and titania deposited on the surface of the ferrite core should be determined depending on the ferrite core particles size and shape. Based on microscopy and XRD analysis, the surface of $\mathrm{Fe}_{3} \mathrm{O}_{4}$ and $\mathrm{CoFe}_{2} \mathrm{O}_{4}$ spinel ferrites was precisely coated titanium(IV) oxide layer, while titania coating on $\mathrm{BaFe}_{12} \mathrm{O}_{19}$ hexagonal ferrite obtained under the same preparation conditions (ferrite: $\mathrm{TiO}_{2}=1: 2$, TEOS:ferrite $=8: 1$ ) was poor and should be further verified by individually adjusting the amount of silica and titania deposited on barium ferrite particles.

Obtained spinel and hexagonal ferrites possess strong ferromagnetic properties. The saturation magnetization $\left(M_{s}\right)$ of $\mathrm{Fe}_{3} \mathrm{O}_{4}, \mathrm{BaFe}_{12} \mathrm{O}_{19}$ and $\mathrm{CoFe}_{2} \mathrm{O}_{4}$ were $89 \mathrm{emu} / \mathrm{g}, 64 \mathrm{emu} / \mathrm{g}$ and $39 \mathrm{emu} / \mathrm{g}$, respectively. For all magnetic nanocomposites, the saturation magnetization values were calculated into emu/gram of the $\mathrm{Fe}_{3} \mathrm{O}_{4} / \mathrm{SiO}_{2} / \mathrm{TiO}_{2}, \mathrm{CoFe}_{2} \mathrm{O}_{4} / \mathrm{SiO}_{2} / \mathrm{TiO}_{2}$ and $\mathrm{BaFe}_{12} \mathrm{O}_{19} / \mathrm{SiO}_{2} / \mathrm{TiO}_{2}$ photocatalyst including the mass of the non-magnetic silica and titania layer. Therefore, decrease in $M_{S}$ for magnetic particles coated with non-magnetic silica and titania was observed. Further, the magnetization values were recalculated using emu/mol of $\mathrm{Fe}_{3} \mathrm{O}_{4}$. The amount of ferrite particles into the structure of the magnetic nanocomposite was determined from XRF analysis and these results were in agreement with the nominal composition of the magnetic photocatalyst which yielded saturation magnetization values only slightly lower (about $14 \%$ ) with respect to uncoated magnetite particles. The decrease in $M_{S}$ can be attributed to the non-magnetic iron oxide $\left(\mathrm{Fe}_{2} \mathrm{O}_{3}\right)$ content [45] or higher surface spin disorder created by $\mathrm{SiO}_{2}$ coating [46]. The critical size of a magnetic single-domain calculated for $\mathrm{Fe}_{3} \mathrm{O}_{4}$ for $M_{S}$ value of $89 \mathrm{emu} / \mathrm{g}$, using exchange stiffness $A=0.7 \mu \mathrm{erg} / \mathrm{cm}(7 \mathrm{pJ} / \mathrm{m})$ [35] was about $250 \mathrm{~nm}$. This value exceeds the limit of a critical radius for superparamagnetic domain of $\mathrm{Fe}_{3} \mathrm{O}_{4}$, which is about $49 \mathrm{~nm}$, as reported by Petracic [36]. On the other hand, the single-domain critical sizes $\left(D_{c r}\right)$ were $67.5 \mathrm{~nm}$ and $24.8 \mathrm{~nm}$ for $\mathrm{BaFe}_{12} \mathrm{O}_{19}$ and $\mathrm{CoFe}_{2} \mathrm{O}_{4}$, respectively and were lower than theoretical values [37,38], suggesting that the obtained $\mathrm{BaFe}_{12} \mathrm{O}_{19}$ and $\mathrm{CoFe}_{2} \mathrm{O}_{4}$ magnetic nanocomposites can reveal superparamagnetic properties. Furthermore, the microscopy TEM/SEM and XRD analyses, as well as $\mathrm{M}(\mathrm{H})$ results indicate the superparamagnetic behavior of the $\mathrm{CoFe}_{2} \mathrm{O}_{4} / \mathrm{SiO}_{2} / \mathrm{TiO}_{2}$ and $\mathrm{BaFe}_{12} \mathrm{O}_{19} / \mathrm{SiO}_{2} / \mathrm{TiO}_{2}$ magnetic photocatalysts.

\section{Experimental Part}

\subsection{Materials}

All reagents used were of analytical grade (purchased from Aldrich, Poznan, Poland) and used without further purification.

Commercial $\mathrm{TiO}_{2} \mathrm{P} 25$ (mixture of the crystalline phases: anatase and rutile, $\mathrm{S}_{\mathrm{BET}}=50 \mathrm{~m}^{2} \mathrm{~g}^{-1}$, particle size: $20 \mathrm{~nm}$, supplier: Evonik, Essen, Germany) was used for preparation of magnetic photocatalysts. Ferrous ferric oxide $\left(50 \mathrm{~nm} ; \mathrm{Fe}_{3} \mathrm{O}_{4}\right.$, Aldrich, Poznan, Poland) made the magnetic core of nanocomposites. $\mathrm{FeCl}_{2} \cdot 4 \mathrm{H}_{2} \mathrm{O}, \mathrm{FeCl}_{3} \cdot 6 \mathrm{H}_{2} \mathrm{O}, \mathrm{FeSO}_{4} \cdot 7 \mathrm{H}_{2} \mathrm{O}, \mathrm{Fe}\left(\mathrm{NO}_{3}\right)_{3} \cdot 9 \mathrm{H}_{2} \mathrm{O}, \mathrm{ZnCl}_{2}, \mathrm{BaNO}_{3}$ were provided by Aldrich (Poznan, Poland), $\mathrm{ZnCl}_{2}$ was provided by Fluka (Bucharest, Romania), and $\mathrm{CoCl}_{3} \cdot 6 \mathrm{H}_{2} \mathrm{O}$ was purchased from POCh (Gliwice, Poland) and used as starting materials for preparation of spinel and hexagonal ferrites. Ammonium hydroxide solution (25\%) was purchased 
from Avantor (Gliwice, Poland Tetraethyl orthosilicate (TEOS) was provided by Aldrich (Poznan, Poland) and used as precursor for preparation of silica-coated magnetic nanoparticles.

Cyclohexane was purchased from Avantor (Gliwice, Poland) and used as the continuous oil phase of $\mathrm{w} / \mathrm{o}$ microemulsion. Cetyltrimethylammonium bromide (CTAB) and $t$-octylphenoxypolyethoxyethanol (Triton X-100), and n-butanol were purchased from Sigma Aldrich (Poznan, Poland) and were used as surfactants and co-surfactant, respectively. Phenol and carbamazepine were provided by Sigma Aldrich and used as model organic pollutants.

\subsection{Preparation of Magnetic Photocatalysts}

The magnetic photocatalysts were obtained in w/o microemulsion system using suitable surfactants, allowing adsorption of the individual layers on the surface of the magnetic core. Microemulsion served as a system of nanoreactors for preparation of ultrafine particles with a narrow size distribution. The aqueous phase nanodroplets are dispersed in the continuous oil phase additionally protected and stabilized against agglomeration by the surfactant at the interface of $\mathrm{w} / \mathrm{o}$. Each droplet is a nanoreactor, wherein the chemical reaction is carried out. This allows for tight control of the shape and size of the obtained particles.

\subsubsection{Preparation of Spinel and Hexagonal Ferrite Particles}

Magnetite $\left(\mathrm{Fe}_{3} \mathrm{O}_{4}\right)$ and $\mathrm{CoFe}_{2} \mathrm{O}_{4}$ belong to the family of spinels. Magnetite with a valence structure of $\left(\mathrm{Fe}^{3+}\right)\left[\mathrm{Fe}^{2+} \mathrm{Fe}^{3+}\right] \mathrm{O}_{4}{ }^{2-}$, one of the most investigated magnetic compound, was obtained by co-precipitation of ferrous and ferric salts at $\mathrm{pH}>8$ using cationic surfactant (CTAB). Ferric chloride hexahydrate and ferrous chloride tetrahydrate (2:1) were dissolved in $500 \mathrm{~cm}^{3}$ de-ionized water. After purging the solution with nitrogen, $0.5 \mathrm{~g} \mathrm{CTAB} \mathrm{in} 10 \mathrm{~cm}^{3}$ of hexane were added followed by addition of $5 \mathrm{M} \mathrm{NaOH}$ to the $\mathrm{pH}$ value of 10 . After $2 \mathrm{~h}$ reaction period, particles were separated magnetically, washed with deionized water and dried at $80^{\circ} \mathrm{C}$ to dry mass.

Spinel cobalt ferrite, $\mathrm{CoFe}_{2} \mathrm{O}_{4}$, hard magnetic material with cubic magnetocrystalline anisotropy, high coercivity, moderate saturation magnetization and physicochemical stability was obtained by co-precipitation of $\mathrm{FeSO}_{4} \cdot 7 \mathrm{H}_{2} \mathrm{O}$ and $\mathrm{CoCl}_{3} \cdot 6 \mathrm{H}_{2} \mathrm{O}$ in the mol ratio of $\mathrm{Co}$ to Fe equaled to 1:2. The precipitation agent, $5 \mathrm{M} \mathrm{NaOH}$, was added to the solution at room temperature in nitrogen atmosphere to $\mathrm{pH}$ value of 10 . The mixture was stirred for $30 \mathrm{~min}$, sealed in a Teflon-lined stainless-steel autoclave and maintained at $200{ }^{\circ} \mathrm{C}$ for $5 \mathrm{~h}$ Obtained particles were separated in external magnetic field, washed with deionized water and dried in $80^{\circ} \mathrm{C}$ to dry mass.

Hexagonal ferrite, $\mathrm{BaFe}_{12} \mathrm{O}_{19}$, magnetic compound, with high resistivity, magneto-crystalline anisotropy and saturation magnetization was prepared by co-precipitation of $\mathrm{Fe}\left(\mathrm{NO}_{3}\right)_{3} \cdot 9 \mathrm{H}_{2} \mathrm{O}$ and $\mathrm{Ba}\left(\mathrm{NO}_{3}\right)_{2}$ with $\mathrm{Fe}$ to $\mathrm{Ba}$ molar ratio equaled to 10 under nitrogen conditions and in the presence of the cationic surfactant (CTAB). After purging the solution with nitrogen gas, $0.5 \mathrm{~g} C \mathrm{CTAB}$ in $10 \mathrm{~cm}^{3}$ of hexane were added followed by addition of precipitation agent $5 \mathrm{M} \mathrm{NaOH}$ to the $\mathrm{pH}$ value of 10 . Obtained precipitate was separated, washed with distilled water, dried at $80{ }^{\circ} \mathrm{C}$, and calcined at $1000{ }^{\circ} \mathrm{C}$ for $2 \mathrm{~h}$.

\subsubsection{Preparation of Spinel and Hexagonal Ferrite Coated with Silica Interlayer and $\mathrm{TiO}_{2}$ Shell}

In this study, the core-shell and core-interlayer-shell magnetic nanocomposites preparation method based on changes in the zeta potential as function of $\mathrm{pH}$ was proposed. The functionalization of magnetic core with silica interlayer and $\mathrm{TiO}_{2}$ photocatalyst layer was carried out in w/o microemulsion system depending on the particles surface charge in aqueous phase in different $\mathrm{pH}$. As shown in Figure 12, magnetic photocatalysts were prepared by two variants of the microemulsion method. In the first variant, presented in Figure 11, magnetic nanoparticles $\left(\mathrm{Fe}_{3} \mathrm{O}_{4}, \mathrm{CoFe}_{2} \mathrm{O}_{4}\right.$ or $\left.\mathrm{BaFe}_{12} \mathrm{O}_{19}\right)$ were dispersed in w/o microemulsion of cationic surfactant cethyltrimethylammonium bromide (CTAB), n-hexanol and aqueous phase. Aqueous solution was prepared by dissolving sodium hydroxide in deionized water to $\mathrm{pH}$ value of 10 . The water content was controlled by fixing the molar ratio 
of water to surfactant at 15 and the volume ratio between oil phase and water phase $(\mathrm{o} / \mathrm{w})$ was 6 . Then, tetraethylorthosilicate (TEOS) dispersed in $20 \mathrm{~cm}^{3}$ microemulsion containing ammonia in aqueous phase was added into microemulsion containing magnetic nanoparticles. The molar ratios of TEOS to ferrite was 8:1 and $\mathrm{NH}_{4} \mathrm{OH}$ to TEOS equaled 16. Obtained $\mathrm{Fe}_{3} \mathrm{O}_{4} / \mathrm{SiO}_{2}$ particles were covered with commercial $\mathrm{TiO}_{2}$ ( $\mathrm{P} 25$, Evonik) or $\mathrm{TiO}_{2}$ obtained by hydrolysis of $\mathrm{TiO}_{2}$ precursor (titanium n-butoxide, TBT) in water cores of microemulsio. In this regard, $\mathrm{TiO}_{2} \mathrm{P}_{2} 5$ powder or $\mathrm{TiO}_{2}$ precursor (TBT) was dispersed in a solution of $\mathrm{CTAB} / \mathrm{n}$-hexanol in molar ratio 1 to 12.6 and added into microemulsion containing ferrite $/ \mathrm{SiO}_{2}$ particles maintaining aqueous phase $(5 \mathrm{M} \mathrm{NaOH})$ $\mathrm{pH}$ value at 10 . The molar ratio of ferrite to $\mathrm{TiO}_{2}$ was $1: 4$ or 1:2. Finally, microemulsion was destabilized with acetone and obtained ferrite $/ \mathrm{SiO}_{2} / \mathrm{TiO}_{2}$ particles were separated, dried at $80{ }^{\circ} \mathrm{C}$ to dry mass and calcined at $400{ }^{\circ} \mathrm{C}$ for $2 \mathrm{~h}$.

a)

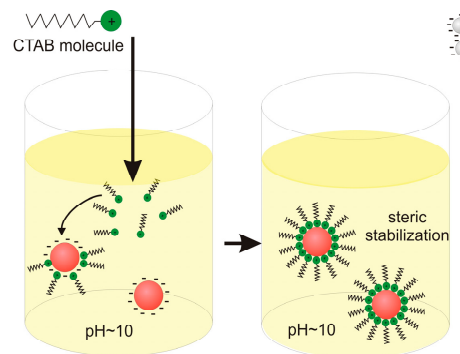

b)

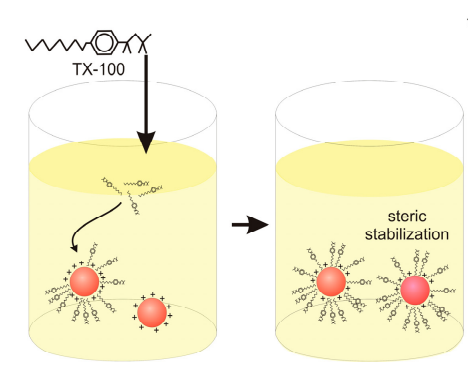

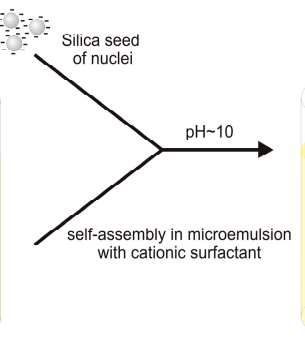

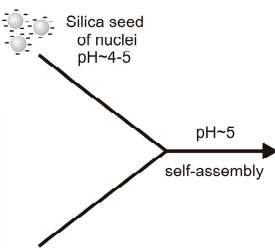

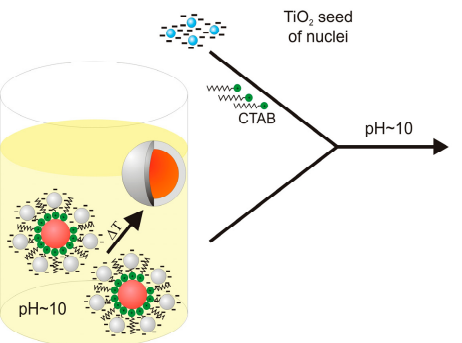

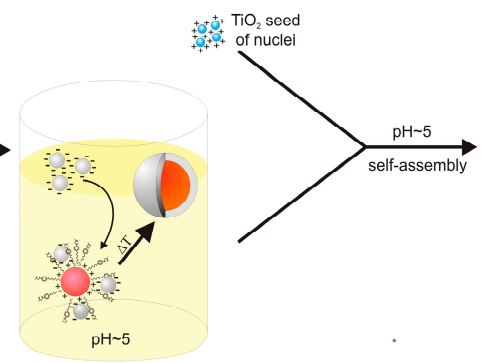

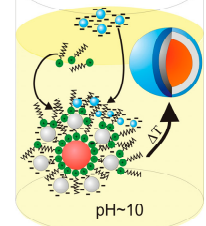

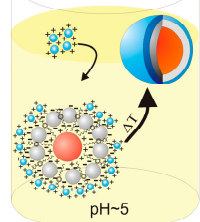

Figure 12. Schematic illustration of magnetic photocatalysts preparation procedure at $\mathrm{pH} 10$ (a) and at $\mathrm{pH} 5$ (b) in w/o microemulsion.

Another option shown in Figure 12b, modification of ferrite $\left(\mathrm{Fe}_{3} \mathrm{O}_{4}, \mathrm{CoFe}_{2} \mathrm{O}_{4}\right.$ or $\left.\mathrm{BaFe}_{12} \mathrm{O}_{19}\right)$ particles with silica interlayer and $\mathrm{TiO}_{2}$ layer, was performed in $\mathrm{TX}-100 /$ water/cyclohexane microemulsion. Firstly, ferrite particles were dispersed in 0.2 M TX-100 in cyclohexane. The water content was controlled by fixing the molar ratio of water to surfactant at 30 and the volume ratio between the oil phase and the aqueous phase $(\mathrm{o} / \mathrm{w})$ was 15 . Then, tetraethylorthosilicate (TEOS) dispersed in microemulsion containing $0.1 \mathrm{M}$ hydrochloric acid in the aqueous phase was added into microemulsion containing magnetic nanoparticles. The molar ratio of TEOS to ferrite was 8:1 and $\mathrm{pH}$ of the aqueous phase was adjusted to 5 . Obtained $\mathrm{Fe}_{3} \mathrm{O}_{4} / \mathrm{SiO}_{2}$ particles were covered with commercial $\mathrm{TiO}_{2}$ (P25, Evonik) or $\mathrm{TiO}_{2}$ obtained by hydrolysis of $\mathrm{TiO}_{2}$ precursor (titanium n-butoxide, TBT) in microemulsion system at $\mathrm{pH}$ of the aqueos phase adjusted to 5 . The molar ratio of ferrite to $\mathrm{TiO}_{2}$ was 1:4 or 1:2. Finally, microemulsion was destabilized with acetone and obtained ferrite $/ \mathrm{SiO}_{2} / \mathrm{TiO}_{2}$ particles were separated, dried at $80{ }^{\circ} \mathrm{C}$ to dry mass and calcined at $400{ }^{\circ} \mathrm{C}$ for $2 \mathrm{~h}$.

\subsection{Characterization of Magnetic Photocatalysts}

XRD analysis were performed using Rigaku Intelligent X-ray diffraction system SmartLab equipped with a sealed tube $X$-ray generator. Data acquisition conditions were as follows: $2 \theta$ range $20-80^{\circ}$, scan speed: $1^{\circ} \cdot \mathrm{min}^{-1}$ and scan step $0.01^{\circ}$. The crystallite size of the photocatalysts in the direction vertical to the corresponding lattice plane was determined using Scherrer's equation 
based on the corrected full width at half maximum (FWHM) of the XRD peak and angle of diffraction. Subtraction of the FWHM of the standard was employed as correction method.

To evaluate the light-absorption properties of modified photocatalysts, the diffuse reflectance (DR) spectra were recorded, and the data were converted to obtain the absorption spectra. The band gap energies of photocatalysts were calculated from the corresponding Kubelka-Munk function, $F(R)=\frac{(1-R)^{2}}{2 R}$, where $R$ is reflectance, which is proportional to the absorption of radiation, by plotting $F(R)^{0.5} \mathrm{E}_{\mathrm{ph}}{ }^{0.5}$ against $\mathrm{E}_{\mathrm{ph}}$, where $\mathrm{E}_{\mathrm{ph}}$ is photon energy. The measurements were carried out on Thermo Scientific Evolution 220 (Waltham, MA, USA) spectrophotometer equipped with PIN-757 integrating sphere.

Nitrogen adsorption-desorption isotherms were recorded at liquid nitrogen temperature (77 K) using Micromeritics Gemini V (model 2365) (Norcross, GA, USA) instrument and the specific surface areas were determined using the Brunauer-Emmett-Teller (BET) method.

XPS analysis was carried out in multichamber ultrahigh vacuum (UHV) system, (Prevac, Rogów, Poland).

The morphology and distribution size of magnetic photocatalysts were observed using Cs-corrected STEM (High Angle Annular Dark Field, HAADF) imaging supplemented with EDXS mapping (JEOL200F, Zaventem, Belgium).

The progress of photocatalytic degradation of organic compounds was measured with application of TOC analyzer (Hach Lange Company, Wroclaw, Poland). The effect of $\mathrm{pH}$ on particles surface charge was measured as zeta potential $(\mathrm{mV})$ using Malvern Nano Zetasizer (Malvern Instruments Ltd., Malvern, UK).

Magnetic hysteresis loops were carried out using Physical Properties Measurements System (PPMS, Quantum Design, San Diego, CA, USA). Measurements were performed at temperature $293 \mathrm{~K}$ in the range of $0-3 \mathrm{~T}$.

\subsection{Measurements of Photocatalytic Activity}

In order to evaluate photocatalytic activity, $50 \mathrm{~cm}^{3}$ of $2 \times 10^{-4} \mathrm{M}$ phenol solution or $6 \times 10^{-5} \mathrm{M}$ carbamazepine solution containing $0.1 \mathrm{~g}$ suspended magnetic photocatalyst was stirred and aerated prior and during the photocatalytic process. The suspension of photocatalyst was irradiated using a Xenon lamp $(6271 \mathrm{H}$, Oriel, CA, USA), emitting UV-vis light. The power flux at UV range (310-380 nm) was $50 \mathrm{~mW} \cdot \mathrm{cm}^{-2}$. The $50 \mathrm{~cm}^{3}$ photoreactor of $3 \mathrm{~cm}$ thickness of exposure layer was equipped with a quartz window. The temperature of the aqueous phase during irradiation was kept at $20^{\circ} \mathrm{C}$ using a water bath. Aliquots of $1.0 \mathrm{~cm}^{3}$ of the aqueous suspension were collected at regular time periods during irradiation and filtered through syringe filters $(\varnothing=0.2 \mu \mathrm{m})$ to remove the photocatalyst particles or isolated by magnetically separation (in cycles of degradation) and washed with water. Phenol concentration was estimated by colorimetric method using Thermo 220 Evolution UV-vis Spectrophotometer (Waltham, MA, USA). Moreover, the progress of phenol and carbamazepine photocatalytic degradation was measured by the total organic carbon (TOC) concentration (TOC Analyzer, Shimadzu, Kyoto, Japan). Photocatalytic degradation runs were preceded by blind test in the absence of a photocatalyst or illumination. No degradation of phenol or carbamazepine was observed in the absence of either the photocatalyst or illumination.

\section{Conclusions}

In this work, we developed a novel method for the preparation of the magnetic photocatalysts with controllable formation core-interlayer-shell structure based on zeta potential changes in aqueous phase. The functionalization of magnetic core with silica interlayer and $\mathrm{TiO}_{2}$ photocatalyst layer was performed in a w/o microemulsion system using non-ionic (TX-100) and cationic (CTAB) surfactants, depending on the particle surface charge in different $\mathrm{pH}$ values. The positively charged ferrite particle can interact in acidic conditions with negatively charged silica, leading to self-assembly of $\mathrm{SiO}_{2}$ into ferrite shell. Indeed, $\mathrm{TiO}_{2}$ nanoparticles are positively charged, and thus, interact competitively 
with silica particles deposited on a ferrite core. In alkaline conditions, cationic surfactant is used as a binder to form a silica shell on a ferrite core. Moreover, the cationic surfactant also effectively interacts with negatively charged titania species, resulting in the core-interlayer-shell structure of nanocomposite. The composition of the core-interlayer-shell structure of magnetic nanocomposites was confirmed by TEM analysis supplemented with EDXS mapping. Based on XRD data crystalline cubic spinel structure of $\mathrm{Fe}_{3} \mathrm{O}_{4}$ and $\mathrm{CoFe}_{2} \mathrm{O}_{4}$, magnetic particles with crystallite size of $45 \mathrm{~nm}$ and $13 \mathrm{~nm}$ was observed. $\mathrm{BaFe}_{12} \mathrm{O}_{19}$ particles were hexagonal in shape with the random orientation and diameters of the aggregated particles in the range of $40-70 \mathrm{~nm}$. The obtained nanocomposites exhibit superparamagnetic behavior. The best photocatalytic activity in the reaction of phenol and carbamazepine photomineralization was observed for the sample $\mathrm{CoFe}_{2} \mathrm{O}_{4} / \mathrm{SiO}_{2} / \mathrm{TiO}_{2} \_$obtained by self-assembly of $\mathrm{SiO}_{2}$ and $\mathrm{TiO}_{2} \mathrm{P} 25$ particles at $\mathrm{pH}=5$ on the surface of cobalt ferrite. This photocatalyst was as effective in the reaction of phenol degradation as $\mathrm{TiO}_{2}$ (P25, Evonik), but more easily separable due to superparamagnetic properties. Photocatalytic activity measured in the fourth subsequent cycle showed good reusability and no loss in phenol degradation.

Acknowledgments: This research was financially supported by Polish National Science Centre (Grant No. NCN 2016/23/D/ST5/01021).

Author Contributions: A.Z.-J.: conceived the concept, designed the experiments, analyzed the data, performed zeta potential and XRD analyses, contributed reagents, materials and analysis tools, and drafted the manuscript; Z.B., I.W., S.D.: performed magnetic photocatalyst synthesis; Z.S.: performed the VSM analysis; T.K.: participated in the analysis and interpretation of magnetic properties; G.N.: performed TEM microscopy analysis, J.H. edited and revised the manuscript.

Conflicts of Interest: The authors declare no conflict of interest.

\section{References}

1. Guo, Z.; Ma, R.; Li, G. Degradation of phenol by nanomaterial $\mathrm{TiO}_{2}$ in wastewater. Chem. Eng. J. 2006, 119, 55-59. [CrossRef]

2. Carabin, A.; Drogui, P.; Robert, D. Photo-degradation of carbamazepine using $\mathrm{TiO}_{2}$ suspended photocatalysts. J. Taiwan Inst. Chem. Eng. 2015, 54, 109-117. [CrossRef]

3. He, Y.; Sutton, N.B.; Rijnaarts, H.H.H.; Langenhoff, A.A.M. Degradation of pharmaceuticals in wastewater using immobilized $\mathrm{TiO}_{2}$ photocatalysis under simulated solar irradiation. Appl. Catal. B Environ. 2016, 182, 132-141. [CrossRef]

4. Zielińska-Jurek, A.; Zaleska, A. Ag/Pt-modified $\mathrm{TiO}_{2}$ nanoparticles for toluene photooxidation in the gas phase. Catal. Today 2014, 230, 104-111. [CrossRef]

5. Vitiello, G.; Pezzella, A.; Zanfardino, A.; Silvestri, B.; Giudicianni, P.; Constantini, A.; Varcamonti, M.; Branda, F.; Luciani, G. Antimicrobial activity of eumelanin-based hybrids: The role of $\mathrm{TiO}_{2}$ in modulating the structure and biological performance. Mater. Sci. Eng. C 2017, 75, 454-462. [CrossRef] [PubMed]

6. Jalvo, B.; Faraldos, M.; Bahamonde, A.; Rosal, R. Antimicrobial and antibiofilm efficacy of self-cleaning surfaces functionalized by $\mathrm{TiO}_{2}$ photocatalytic nanoparticles against Staphylococcus aureus and Pseudomonas putida. J. Hazard. Mater. 2017, 340, 160-170. [CrossRef] [PubMed]

7. Xue, X.-D.; Fu, J.-F.; Zhu, W.-F.; Guo, X.-C. Separation of ultrafine $\mathrm{TiO}_{2}$ from aqueous suspension and its reuse using cross-flow ultrafiltration (CFU). Desalination 2008, 225, 29-40. [CrossRef]

8. Zielińska-Jurek, A.; Klein, M.; Hupka, J. Enhanced visible light photocatalytic activity of $\mathrm{Pt} / \mathrm{I}-\mathrm{TiO}_{2}$ in a slurry system and supported on glass packing. Sep. Purif. Technol. 2017, 189, 246-252. [CrossRef]

9. Dijkstra, M.F.J.; Michorius, A.; Buwalda, H.; Panneman, H.J.; Winkelman, J.G.M.; Beenackers, A.A.C.M. Comparison of the efficiency of immobilized and suspended systems in photocatalytic degradation. Catal. Today 2001, 66, 487-494. [CrossRef]

10. Yang, L.; Wang, F.; Hakki, A.; Macphee, D.E.; Liu, P.; Hu, S. The influence of zeolites fly ash bead/ $/ \mathrm{TiO}_{2}$ composite material surface morphologies on their adsorption and photocatalytic performance. Appl. Surf. Sci. 2017, 392, 687-696. [CrossRef] 
11. Ilkaeva, M.; Krivtsov, I.; Díaz, E.; Amghouzd, Z.; Pati, E.; Khainakove, S.; Garcíaa, J.S.; Ordónez, S. Photocatalytic degradation of 2-(4-methylphenoxy)ethanol over $\mathrm{TiO}_{2}$ spheres. J. Hazard. Mater. 2017, 332, 59-69. [CrossRef] [PubMed]

12. Tsai, M.-C.; Yang, M.-H.; Chang, Y.-W.; Tzeng, J.-K.; Lee, C.-Y.; Chiu, H.T.; Chen, H.-C.; Lin, I.-N. Synthesis of porous micro-sized titania cages and their photocatalytic property. Mater. Chem. Phys. 2013, 143, 60-64. [CrossRef]

13. Dou, L.; Gao, L.; Yang, X.; Song, X. Hierarchical architectures $\mathrm{TiO}_{2}$ : Pollen-inducted synthesis, remarkable crystalline-phase stability, tunable size, and reused photo-catalysis. J. Hazard. Mater. 2012, 203-204, 363-369. [CrossRef] [PubMed]

14. Hiroshi, F.; Yukiko, H.; Michichiro, Y.; Shoichi, A. Magnetic Photocatalyst. Japanese Patent JP6154620, 13 February 1994.

15. Towata, A.; Sando, M. Photocatalyst Particles Containing Ferromagnetic Metal Particles and Method for Synthesis Thereof. U.S. Patent 5,703,002, 30 August 1997.

16. Beydoun, D.; Amal, R.; Low, G.; McEvoy, S. A Preliminary Investigation into the Synthesis of Titania-Coated Magnetite as a Novel Photocatalyst. In Proceedings of the Third World Congress on Particle Technology, Brighton, UK, 6-9 July 1998; p. 385.

17. Abbas, M.; Rao, B.P.; Reddy, V.; Kim, C. $\mathrm{Fe}_{3} \mathrm{O}_{4} / \mathrm{TiO}_{2}$ core/shell nanocubes: Single-batch surfactantless synthesis, characterization and efficient catalysts for methylene blue degradation. Ceram. Int. 2014, 40, 11177-11186. [CrossRef]

18. Wei, J. Synthesis and magnetorheological effect of $\mathrm{Fe}_{3} \mathrm{O}_{4}-\mathrm{TiO}_{2}$ nanocomposite. J. Phys. Conf. Ser. 2009, 149, 25-29. [CrossRef]

19. Zhang, L.; Wu, Z.; Chen, L.; Zhang, L.; Li, X.; Xu, H.; Wang, H.; Zhu, G. Preparation of magnetic $\mathrm{Fe}_{3} \mathrm{O}_{4} / \mathrm{TiO}_{2} / \mathrm{Ag}$ composite microspheres with enhanced photocatalytic activity. Solid State Sci. 2016, 52, 42-48. [CrossRef]

20. Beydoun, D.; Amal, R.; Low, G.K.-C.; McEvoy, S. Novel Photocatalyst: Titania-Coated Magnetite. Activity and Photodissolution. J. Phys. Chem. B 2000, 104, 4387-4396. [CrossRef]

21. Fan, Y.; Ma, C.; Li, W.; Yin, Y. Synthesis and properties of $\mathrm{Fe}_{3} \mathrm{O}_{4} / \mathrm{SiO}_{2} / \mathrm{TiO}_{2}$ nanocomposites by hydrothermal synthetic method. Mater. Sci. Semicond. Process. 2012, 15, 582-585. [CrossRef]

22. Gad-Allah, T.A.; Fujimura, K.; Kato, S.; Satokawa, S.; Kojima, T. Preparation and characterization of magnetically separable photocatalyst $\left(\mathrm{TiO}_{2} / \mathrm{SiO}_{2} / \mathrm{Fe}_{3} \mathrm{O}_{4}\right)$ : Effect of carbon coating and calcination temperature. J. Hazard. Mater. 2008, 154, 572-577. [CrossRef] [PubMed]

23. Shi, F.; Li, Y.; Zhang, Q.; Wang, H. Synthesis of $\mathrm{Fe}_{3} \mathrm{O}_{4} / \mathrm{C} / \mathrm{TiO}_{2}$ magnetic photocatalyst via vapor phase hydrolysis. Int. J. Photoenergy 2012, 2012, 1-8. [CrossRef]

24. Yuan, Q.; Li, N.; Geng, W.; Chi, Y.; Li, X. Preparation of magnetically recoverable $\mathrm{Fe}_{3} \mathrm{O}_{4} @ \mathrm{SiO}_{2} @ \mathrm{meso}^{-\mathrm{TiO}_{2}}$ nanocomposites with enhanced photocatalytic ability. Mater. Res. Bull. 2012, 47, 2396-2402. [CrossRef]

25. Li, R.; Jia, Y.; Bu, N.; Wu, J.; Zhen, Q. Photocatalytic degradation of methyl blue using $\mathrm{Fe}_{2} \mathrm{O}_{3} / \mathrm{TiO}_{2}$ composite ceramics. J. Alloys Compd. 2015, 643, 88-93. [CrossRef]

26. Lee, S.; Drwiega, J.; Wu, C.; Mazyck, D.; Sigmund, W.M. Anatase $\mathrm{TiO}_{2}$ Nanoparticle Coating on Barium Ferrite Using Titanium Bis-Ammonium Lactato Dihydroxide and Its Use as a Magnetic Photocatalyst. Chem. Mater. 2004, 12, 1160-1164. [CrossRef]

27. Li, H.; Zhang, Y.; Wang, S.; Wu, Q.; Liu, C. Study on nanomagnets supported $\mathrm{TiO}_{2}$ photocatalysts prepared by a sol-gel process in reverse microemulsion combining with solvent-thermal technique. J. Hazard. Mater. 2009, 169, 1045-1053. [CrossRef] [PubMed]

28. Salamat, S.; Younesi, H.; Bahramifar, N. Synthesis of magnetic core-shell $\mathrm{Fe}_{3} \mathrm{O}_{4} @ \mathrm{TiO}_{2}$ nanoparticles from electric arc furnace dust for photocatalytic degradation of steel mill wastewater. RSC Adv. 2017, 7, 19391-19405. [CrossRef]

29. Prieto-Mahaney, O.O.; Murakami, N.; Abe, R.; Ohtani, B. Correlation between Photocatalytic Activities and Structural and Physical Properties of Titanium(IV) Oxide Powders. Chem. Lett. 2009, 38, 238-239. [CrossRef]

30. Amano, F.; Nakata, M.; Yamamoto, A.; Tanaka, T. Rutile titanium dioxide prepared by hydrogen reduction of Degussa P25 for highly efficient photocatalytic hydrogen evolution. Catal. Sci. Technol. 2016, 6, 5693-5699. [CrossRef]

31. Fagerlund, G. Determination of specific surface by the BET method. Mater. Constr. 1973, 6, $239-245$. [CrossRef] 
32. Liu, H.; Jia, Z.; Ji, S.; Zheng, Y.; Li, M.; Yang, H. Synthesis of $\mathrm{TiO}_{2} / \mathrm{SiO}_{2} @ \mathrm{Fe}_{3} \mathrm{O}_{4}$ magnetic microspheres and their properties of photocatalytic degradation dyestuff. Catal. Today 2011, 175, 293-298. [CrossRef]

33. Chi, Y.; Yuan, Q.; Li, Y.; Zhao, L.; Li, N.; Li, X.; Yan, W. Magnetically separable $\mathrm{Fe}_{3} \mathrm{O}_{4} @ \mathrm{SiO}_{2} @ \mathrm{TiO}_{2}-\mathrm{Ag}$ microspheres with well-designed nanostructure and enhanced photocatalytic activity. J. Hazard. Mater. 2013, 262, 404-411. [CrossRef] [PubMed]

34. Fu, W.; Yang, H.; Li, M.; Chang, L.; Yu, Q.; Xu, J.; Zou, G. Preparation and photocatalytic characteristics of core-shell structure $\mathrm{TiO}_{2} / \mathrm{BaFe}_{12} \mathrm{O}_{19}$ nanoparticles. Mater. Lett. 2006, 60, 2723-2727. [CrossRef]

35. Dubowik, J.; Gościańska, I. Micromagnetic Approach to Exchange Bias. Acta Phys. Pol. A 2015, 127, $147-152$. [CrossRef]

36. Petracic, O. Superparamagnetic nanoparticle ensembles. Superlattices Microstruct. 2010, 47, 569-578. [CrossRef]

37. Haneda, K.; Morrish, A.H. Magnetic Properties of $\mathrm{BaFe}_{12} \mathrm{O}_{19}$ Small Particles. IEEE Trans. Magn. 1989, 25, 2597-2601. [CrossRef]

38. Torres, T.E.; Lima, E., Jr.; Mayoral, A.; Ibarra, A.; Marquina, C.; Ibarra, M.R.; Goya, G.F. Validity of the Néel-Arrhenius model for highly anisotropic $\mathrm{Co}_{x} \mathrm{Fe}_{3-x} \mathrm{O}_{4}$ nanoparticles. J. Appl. Phys. 2015, 118, 183902. [CrossRef]

39. Su, R.; Bechstein, R.; Sø, L.; Vang, R.T.; Sillassen, M.; Esbjörnsson, B.; Palmqvist, A.; Besenbacher, F. How the Anatase-to-Rutile Ratio Influences the Photoreactivity of $\mathrm{TiO}_{2}$. J. Phys. Chem. C 2011, 115, 24287-24292. [CrossRef]

40. Ohno, T.; Sarukawa, K.; Tokieda, K.; Matsumura, M. Morphology of a $\mathrm{TiO}_{2}$ Photocatalyst (Degussa, P-25) Consisting of Anatase and Rutile Crystalline Phases. J. Catal. 2001, 203, 82-86. [CrossRef]

41. Rui, Z.; Wu, S.; Peng, C.; Ji, H. Comparison of $\mathrm{TiO}_{2}$ Degussa P25 with anatase and rutile crystalline phases for methane combustion. Chem. Eng. J. 2014, 243, 254-264. [CrossRef]

42. Kawahara, T.; Konishi, Y.; Tada, H.; Tohge, N.; Nishii, J.; Ito, S. A Patterned $\mathrm{TiO}_{2}\left(\right.$ Anatase) $/ \mathrm{TiO}_{2}(\mathrm{Rutile})$ Bilayer-Type Photocatalyst: Effect of the Anatase/Rutile Junction on the Photocatalytic Activity. Angew. Chem. 2002, 114, 2935-2937. [CrossRef]

43. Zielińska-Jurek, A.; Wei, Z.; Wysocka, I.; Szweda, P.; Kowalska, E. The effect of nanoparticles size on photocatalytic and antimicrobial properties of Ag-Pt/ $\mathrm{TiO}_{2}$ photocatalysts. Appl. Surf. Sci. 2015, 353, 317-325. [CrossRef]

44. Zielińska-Jurek, A.; Bielan, Z.; Wysocka, I.; Strychalska, J.; Janczarek, M.; Klimczuk, T. Magnetic semiconductor photocatalysts for the degradation of recalcitrant chemicals from flow back water. J. Environ. Manag. 2017, 195, 157-165. [CrossRef] [PubMed]

45. Zhen, G.; Muir, B.W.; Moffat, B.A.; Harbour, P.; Murray, K.S.; Moubaraki, B.; Suzuki, K.; Madsen, I.; Agron-Olshina, N.; Waddington, L. Comparative study of magnetic behavior of spherical and cubic superparamagnetic iron oxide nanoparticles. J. Phys. Chem. C 2011, 115, 327-334. [CrossRef]

46. Larumbe, S.; Gómez-Polo, C.; Pérez-Landazábal, J.; Pastor, J.M. Effect of a $\mathrm{SiO}_{2}$ coating on the magnetic properties of $\mathrm{Fe}_{3} \mathrm{O}_{4}$ nanoparticles. J. Phys. Condens Matter. 2012, 24, 1-6. [CrossRef] [PubMed]

(C) 2017 by the authors. Licensee MDPI, Basel, Switzerland. This article is an open access article distributed under the terms and conditions of the Creative Commons Attribution (CC BY) license (http://creativecommons.org/licenses/by/4.0/). 